\title{
User's Guide to the MESOI Diffusion Model and to the Utility Programs UPDATE and LOGRVU
}

\author{
G. F. Athey \\ K. J. Allwine \\ J. V. Ramsdell
}

November 1981

Prepared for the U.S. Department of Energy under Contract DE-AC06-76RLO 1830

Pacific Northwest Laboratory Operated for the U.S. Department of Energy by Battelle Memorial Institute 
NOTICE

This report was prepared as an account of work sponsored by the United States Government. Neither the United States nor the Department of Energy, nor any of their employees, nor any of their contractors, subcontractors, or their employees. makes any warranty. express or implied, or assumes any legal liability or responsibility for the accuracy, completeness or usefulness of any information. apparatus. product or process disclosed. or represents that its use would not infringe privately owned rights.

The views, opinions and conclusions contained in this report are those of the contractor and do not necessarily represent those of the United States Government or the United States Department of Energy.

\title{
PACIFIC NORTHWEST LABORATORY \\ operated by \\ BATTELLE \\ for the \\ UNITED STATES DEPARTMENT OF ENERGY \\ Under Contract DE-AC06-76RLO 1830
}

\author{
Printed in the United States of America \\ Available from \\ National Technical Information Service \\ United States Department of Commerce \\ 5285 Port Royal Road \\ Springfield. Virginia 22151
}

Price: Printed Copy \$

$\therefore$ Microfiche $\$ 3.00$

$\begin{array}{cc}\text { •Pages } & \begin{array}{c}\text { NTIS } \\ \text { Selling Pric }\end{array} \\ \text { 001-025 } & \$ 4.00 \\ 026-050 & \$ 4.50 \\ 051-075 & \$ 5.25 \\ 076-100 & \$ 6.00 \\ 101-125 & \$ 6.50 \\ 126-150 & \$ 7.25 \\ 151-175 & \$ 8.00 \\ 176-200 & \$ 9.00 \\ 201-225 & \$ 9.25 \\ 226-250 & \$ 9.50 \\ 251-275 & \$ 10.75 \\ 276-300 & \$ 11.00 \\ & \end{array}$




\section{6}

USER'S GUIDE TO THE MESOI DIFFUSION MODEL AND TO THE UTILITY PROGRAMS UPDATE AND LOGRVU

G. F. Athey

K. J. Allwine

J. V. Ramsde 11

November 1981

Prepared for

the U. S. Department of Energy

under Contract DE-ACO6-76RLO 1830

Pacific Northwest Laboratory

Richland, Washington 99352 


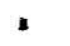

r

.

, 


\section{ABSTRACT}

MESOI is an interactive, Lagrangian puff trajectory diffusion model. The model is documented separately (Ramsdell and Athey, 1981); this report is intended to provide MESOI users with the information needed to successfully conduct model simulations. The user is also provided with guidance in the use of the data file maintenance and review programs; UPDATE and LOGRVU. Complete examples are given for the operation of a 11 three programs and an appendix documents UPDATE and LUGRVU. 


\section{CONTENTS}

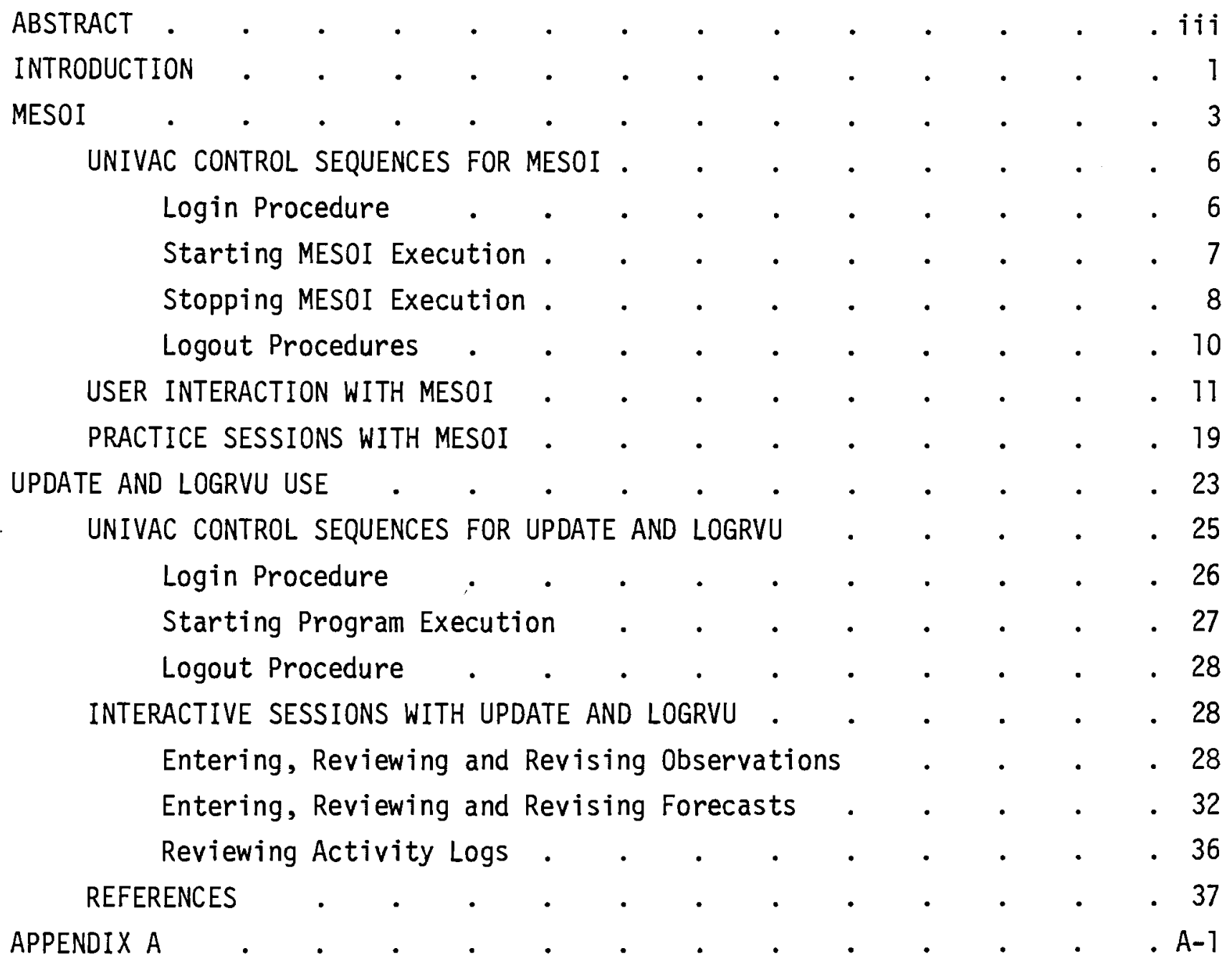



USER'S GUIDE TO THE MESOI DIFFUSION MODEL AND TO THE

UTILITY PROGRAMS UPDATE AND LOGRVU

\section{INTRODUCTION}

MESOI is an interactive, Lagrangian puff trajectory diffusion model. It is an interactive version of the MESO model, and both models are direct derivatives of the Lagrangian puff trajectory model developed by Start and Wendell (1974) for the National Reactor Testing Station in Idaho. The MESOI model is documented separately (Ramsdell and Athey, 1981); this report is intended to provide MESOI users with the information needed to successfully conduct model simulations. The user is also provided with guidance in the use of the utility programs UPDATE and LOGRVU. UPDATE maintains files of meteorological observations and forecasts for use by MESOI, and LOGRVU provides a means of monitoring UPDATE use.

The user's guide is divided into two parts, the first deals with MESOI, and the second covers UPDATE and LOGRVU. Each part starts with a description of the program as it appears to the user in an interactive session. This discussion is followed by instruction in the details of program execution and covers accessing the computer, starting program execution, entering required information and signing-off the computer. Complete examples are given in each part. An appendix contains a short discussion of the UPDATE and LOGRVU programs and a complete listing of each program. 
,

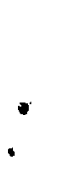

,

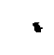


MESOI (Version 1.0, October 1981)

MESOI is designed to operate on the Boeing Computer Services Richland (BCSR) UNIVAC 1100 with communication via a video display terminal and modem. The program uses video terminal cursor control that may be unique to a Televideo 912 terminal. However, no unusual output problems should occur with other terminals. No card input is required: all information is entered from the terminal keyboard. Once execution of MESOI is started, all the user must do is respond to prompts for information. The program contains a set of default conditions which can greatly simplify startup.

Interactive sessions with MESOI consist of three phases: initialization, simulation and output. In the initialization phase the user has the opportunity to modify the wind grid, specify model control parameters, enter off-grid receptors at positions of interest and specify source parameters. The simulation pauses at the end of each hour to give the user the opportunity to view the results. Several output options are available at this time. The user may also choose to continue the simulation for another hour or stop the simulation.

Figure 1 shows the general flow of MESOI. Most of the user-model interaction takes place during the initialization phase. Once an interactive session begins the user is led through the initialization phase by a series of computer prompts requesting information. The first set of prompts deals with the wind grid. MESOI has a default grid that consists of a $16 \times 16$ array of points with a $5 \mathrm{~km}$ spacing between points. If the default grid is satisfactory, no change is necessary. Otherwise, a new spacing can be entered .

There are 22 predefined wind stations within the MESOI grid. If these stations are operational, their status is set to 0 ; a status other than 0 indicates that the station is not operational. The default status for the wind stations is 0 . The user may add new wind stations to a total of 30 . New stations may also be substituted for predefined stations.

When the user is satisfied with the wind stations, the program asks if the user wishes to change the wind interpolation radius. The interpolation radius 

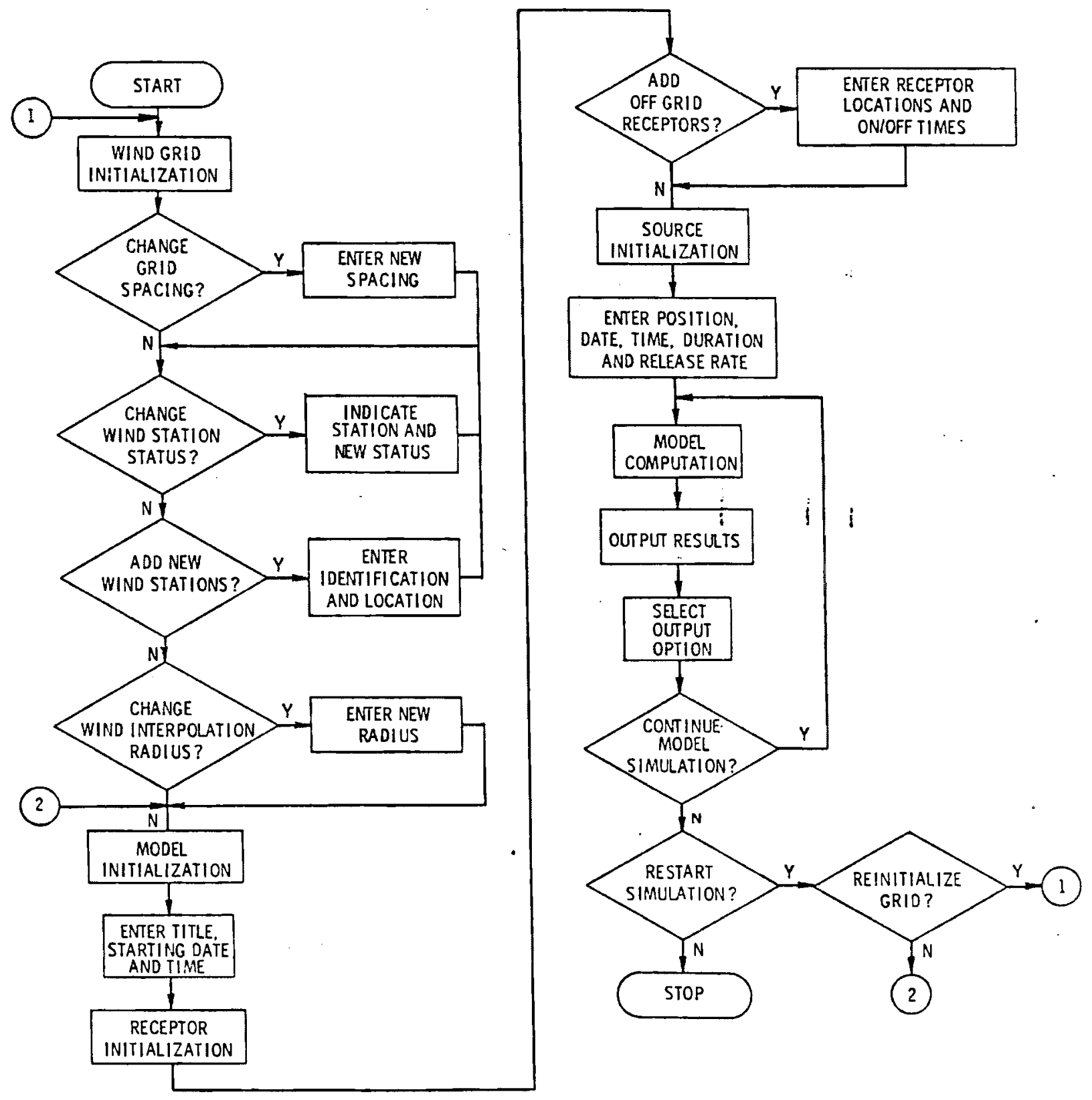

FIGURE 1. General Flow of MESOI 
is the maximum distance, in grid units, that the program will normally search for wind stations for use in the wind interpolation at grid points. The default interpolation radius is 5 grid units ( $25 \mathrm{~km}$ with the default grid spacing). Increasing the radius corresponds to an implicit assumption that the wind stations are representative for larger distances. An increase may be required if low data recovery rates limit the number of stations for which data are available.

Once the wind grid initialization is complete, the computer requests information on the simulation to be completed. This information includes a descriptive title and the date and time for starting the wind field interpolation. Wind field interpolation takes place hourly, and may be begun prior to the time of release.

During the modification of MESO, provision was made for the addition of receptors at off-grid locations. As many as ten of these receptors can be added during the initialization phase by specifying the receptor locations and their time schedule. Exposures at the off-grid receptors are computed by interpolation from surrounding grid points. These exposures may cover periods from 1 to 24 hours in duration. The use of off-grid receptors is optional.

Source initialization completes the initialization phase. In source initialization, the user specifies the release position relative to the Hanford Meteorological Station and a date and time for the start of the release. If the release is of finite duration, the duration may be entered. If the duration of release is unknown, a continuous release is assumed as a default condition. If the release rate is known it may also be entered. In the event that the release rate is unknown (likely in most cases), a unit release rate is included as a default option.

As soon as the initialization phase is completed, the program automatically enters the simulation phase. The simulation is interrupted each hour to provide the user with an opportunity to view the results. Options available to the user at this time include a display on the terminal screen and/or printer output. If the display option is selected, the program pauses following the data presentation. The simulation resumes on user command. The user may also choose to exit at this point. 
The instruction sequences needed to gain access to the UNIVAC computer, to start and stop MESOI execution and to terminate the connection with the UNIVAC are fully described in the next section. They are followed by an example that shows the computer prompts and user responses for an interactive session. The example is annotated to clarify the meaning of the prompts and responses where there might be confusion. Four data sets, assembled to provide users with practice in the use of MESOI, are described at the end of the discussion of MESOI.

UNIVAC CONTROL SEQUENCES FOR MESOI

Use of MESOI model requires access to the UNIVAC computer operated for the Department of Energy by BCSR. This section provides instructions on how to gain access to the computer, start program execution, terminate program execution and disconnect the computer. It consists of step-by-step instructions with both computer messages to the user and appropriate user responses.

Messages from the computer and responses are shown in upper case characters. Responses can be distinguished from messages because they end with a carriage return, which is indicated by the symbol $\langle C R>$. If an error is made in any response and is noticed before the $\langle C R\rangle$, it can be corrected by using the backspace key and retyping the entry from the point of the error. The system prompt character " $>$ " indicates that the computer expects a response from the user. Responses that indicate computer account numbers, project identifications, and terminal identifications, etc., show the proper form for the response. The numbers are, of course, fictitious. Each user must make arrangements with BCSR for a set of correct identification numbers.

Annotation interspersed with the computer messages and user responses can be identified by the normal combination of upper and lower case characters.

\section{LOGIN Procedure}

MESOI is available on System B of the BCSR UNIVAC via a dial-up connection. The following steps permit the user to gain access to the computer. 
1. Check that modem and terminal are set for proper baud rate.

2. Dial the UNIVAC computer number (376-7676 for 1200 baud port).

3. When the carrier signal is heard, depress data button on phone and hang up. The computer should respond with: PORT_SIGNON - SYSA(4 42$)$ UP SYSB $(4 \times 2)$ UP

TYPE TID or OO HOST CARD

4. Type: @@HOST SYSB TID $\langle C R>$

where TID = terminal ID, e.g., CRTI23

If SYSB is available the computer should respond:

ENTER USERID/PASSWORD

$>$

If the connection is terminated or there is no response, try again immediately. If there are continued problems, call BCSR Customer Service on $376-7804$.

5. Type in ID and password, e.g., BCW122/ABC <CR>

Computer responds: ENTER PROJECT-ID

$>$

6. Type a $\langle C R>$ unless your account requires a separate entry.

7. Type in user name and address, e.g., LJ JONES/BNW 622R <CR>

The computer will respond with system bulletins and then give the system prompt ' $>$ '. You are now ready to run programs.

Starting MESOI Execution

The execution of MESOI, discussed in the following section, requires two data files. They are an observed meteorological data file (MDATA.) and a forecast data file (FDATA.). Programs UPDATE and LOGRVU may be used to make sure these files are available and contain current information. Once access to the UNIVAC has been established, a single command line CADD MESOGO. starts the interactive session. The command AADD MESOGO. initiates the following command sequence: 
Command

DASG,A MDATA. QUSE $10 .$, MDATA. QASG, A FDATA. QUSE $11 .$, FDATA
Purpose

Attaches the observation and forecast data files and assigns

Opens files for output listings and temporary data storage; assigns logical unit numbers

Executes the absolute version of the MESOI. code

\section{logical unit numbers}

QASG, UP OUTL.

QUSE 12., OUTL. QASG,UP TEMP7. QUSE 7., TEMP7. QASG UP TEMP9. QUSE $9 .$, TEMP9.

QXQT MESOI.

The system should respond with 10 READY messages, clear the screen, then display the MESOI header message.

\section{Stopping MESOI Execution}

The model execution stops normally under the following circumstances:

48 hours of simulation

user selected termination (output option=4)

various data or input errors

In these cases, messages make it clear that processing has stopped. They are followed by the system prompt ' $>$ '.

At some time it may become necessary to stop execution at a nonstandard point. If the program is producing output to the screen; hit the break key until the system responds with OUTPUT INTERRUPT. When the system is awaiting input, key in

QQX TIOC <CR>

This returns control to the user.

Following an abnormal termination of MESOI, the data files must be reset if an immediate restart is desired. This is accomplished with the command OADD FREDEL. It frees all logical units and deletes all files created during the run. The command CADD FREDEL adds the following string of commands: 
OFREE 10.

QFREE 11 .

QFREE 12.

OFREE 7.

QFREE 9.

DDELETE OUTL.

QDELETE TEMP7.

DDELETE TEMP9.

The AADD FREDEL. command may also be used to delete printer output following normal program termination. To assure that all files are properly set for future model executions, after a normal termination the command OADD MESOND1. $\langle C R>$ is available. It adds the following sequence:

Command

\section{QFREE 7.}

QFREE 9.

@FREE MDATA.

QFREE FDATA.

QFREE OUTL.

@SYM OUTL., 1, RMSUD6

QSTART CONTURI.

¿ASG, A MSG1.

QUSE 20., MSG1.

QXQT REMIND.
Purpose

release all files in use

route output listing to $622 \mathrm{R}$ printer

submit a batch job to run the NEWCONTUR program

attach the proper message file and execute the reminder program

There are two versions of the end routines: MESOND1. and MESOND2. MESOND1. is designed to be used for practice or routine executions. MESOND2. routes output to both the 622R printer and the BCSR printer in the Federal Building. This second routine uses the ' 2 ' versions of CONTUR and MSG.

Each time the ending commands are added, a batch job is submitted to execute the NEWCONTUR program. Documentation of NEWCONTUR is not available. The command structure of the CONTUR file is shown as follows: 
Command

QRUN CONTUR, BCW / $\mathrm{BCW} /, \mathrm{BCW}$.

OIDENT . name/address

OASG, A TEMP7.

QUSE $7 .$, TEMP7.

QASG,A TEMP9.

QUSE 9., TEMP9.

QASG,UP TEMP.

QBRKPT PRINT\$/TEMP

QXQT BCW643 * NEWCONTUR.

QBRKPT PRINT\$

@FREE 7.

OFREE 9.

QDELETE TEMP9.

QDELETE TEMP7.

QFREE TEMP.

QSYM TEMP., 1,RMSU06

QEND
Purpose

Name of user/location of user

attach the files created by MESOI and assign logical unit numbers

open an output file

execute NEWCONTUR, putting output into file marked TEMP

release and delete the files

release TEMP file and route to printer

After the batch job is entered, the REMIND program is executed. It displays the contents of the message file (MSG1. or MSG2.) on the terminal screen. It serves to acknowledge submission of the NEWCONTUR job and to remind the user of any further actions that might be required. The message files can be changed by editing the file. Lines of up to 80 characters are acceptable to the REMIND program.

After adding either version of MESOND, the user may start execution again with the OADD MESOGO. command, proceed to other work, or logout.

Problems can occur when a user uses successive sequences of MESOGO and MESOND_. or EXPGO_. and EXPND_. Each time execution is started, the output file OUTL. is created. Normally, the file is printed immediately and automatically deleted following program termination. If the printer is down or offline, the system retains the file, and an error message will occur when MESOI tries to write the existing OUTL. file. The error message will generally be:

FTN ERR ON UNIT 12

STATUS CODE $X X$

The program terminates upon this error. Before MESOI can be run again, the user must correct the problem by either having the file printed or removing it from the output queue. 


\section{$\underline{\text { Logout Procedures }}$}

When the user completes work on the system, the following sequence of commands is used to logout.

1. If a summary of terminal session charges is desired, proceed to step \#2. If not, enter

QDSKIP $20<C R>$

System will respond with '>'

2. Enter QFIN $\langle$ CR>

System responds with 'TERMINAL INACTIVE'

3. Enter OQTERM $\langle\mathrm{CR}>$

Phone connection should be broken automatically.

USER INTERACTION WITH MESOI

When the user enters the CADD MESOGO. command the UNIVAC will attach the files needed by MESOI and assign the logical unit numbers to disk drives. Successful completion of these tasks is signaled by the 10 READY messages from the computer. The messages are cleared from the screen and the MESOI header message shown below is displayed. The prompt symbol indicates that the computer is ready to begin interactive data entry.

Data entry is relatively simple. If illegal characters are entered, the program prompts for input again. If more than one value is requested, the values may be entered with commas between values or individually in response to multiple prompts. Where possible (e.g., dates or times), checks are made to assure that realistic numbers have been entered. After extensive entry of information, user review usually occurs. However, with single parameter entries, only one opportunity for change is provided. If a bad value is entered and accepted by the program, the user may have no choice but to terminate execution and restart.

MESOI is set up with the following conditions as default: wind grid size of $16 \times 16$ grid spacing of 5000 meters 22 wind stations; all active interpolation radius of 5 grid units no off-grid receptors source term unknown--unit release 
These conditions are used unless changed by the user. Dates, times and titles must be entered for each simulation.

The following example illustrates the prompts and responses during execution of MESOI. The grid size and spacing will remain the same. Two stations will be disabled and three new stations added. Simulation starts at 5 AM on June 3, 1981. Two off-grid receptors are set up to operate between 7 AM and 2 PM. A unit release of 4 hours duration beginning at $5 \mathrm{AM}$ on June $3 \mathrm{rd}$ is simulated.

After entry of @ADD EXPG01., the following sequence occurs: (carriage returns are assumed after all user entries and pauses). The OADD EXPGO1. command is used to gain access to one of the sets of test data.

MESOI - THE INTERACTIVE VERSION OF MESO

$$
\text { VERSION } 1.0 \quad \text { OCTOBER } 1981
$$$$
\text { TIME }=093027 \text { (current time) }
$$$$
\text { DATE }=082681 \text { (current date) }
$$

PAUSE HIT RETURN TO CONTINUE >

MESO $\rightarrow$ GRID INITIALIZATION

THE CURRENT WIND GRID IS:

16 ROWS 16 COLUMNS

DELXY $=5000$ METERS

DO YOU WANT A DIFFERENT GRID SPACING? Y OR N

$>Y$

SPECIFY NEW DELTA XY (IN METERS)

$>1000$

MESO-- $\rightarrow$ STATION INITIALIZATION

THERE ARE CURRENTLY 22 STATIONS WITH O DISABLED

$\begin{array}{lcrrc} & \text { STA NAME } & \text { GRIDX } & \text { GRIDY } & \text { STATUS } \\ 1 & \text { PROS } & 9.80 & 4.40 & 0 \\ 2 & \text { EOC } & 8.70 & 4.60 & 0 \\ 3 & \text { ARMY } & 8.30 & 6.00 & 0 \\ 4 & \text { RSPG } & 6.20 & 6.80 & 0 \\ 5 & \text { EDNA } & 10.10 & 7.90 & 0 \\ 6 & \text { 200E } & 8.60 & 7.50 & 0 \\ 7 & \text { 20OW } & 7.20 & 7.20 & 0 \\ 8 & \text { WAHL } & 4.90 & 11.10 & 0\end{array}$




$\begin{array}{rrrrc}\text { STA NAME } & \text { GRIDX } & \begin{array}{c}\text { GRIDY } \\ \text { (contd) }\end{array} & \begin{array}{r}\text { (contd) } \\ \text { (contd) }\end{array} & \begin{array}{c}\text { STATUS } \\ \text { (contd) }\end{array} \\ 9 & \text { FFTF } & 9.70 & 5.20 & 0 \\ 10 & \text { YAKB } & 6.00 & 7.90 & 0 \\ 11 & \text { 30OA } & 11.30 & 4.20 & 0 \\ 12 & \text { WYEB } & 9.90 & 5.90 & 0 \\ 13 & \text { 10ON } & 7.90 & 9.50 & 0 \\ 14 & \text { WPPS } & 11.10 & 5.60 & 0 \\ 15 & \text { FRNK } & 12.10 & 5.00 & 0 \\ 16 & \text { GABL } & 9.00 & 8.20 & 0 \\ 17 & \text { RING } & 11.60 & 7.10 & 0 \\ 18 & \text { RICH } & 11.20 & 3.10 & 0 \\ 19 & \text { SAGE } & 11.10 & 9.20 & 0 \\ 20 & \text { RMTN } & 7.70 & 3.60 & 0 \\ 21 & \text { HMS } & 7.50 & 7.50 & 0 \\ 22 & \text { PASC } & 13.80 & 2.10 & 0\end{array}$

ANY CHANGES TO STATUS FLAGS? Y OR N

$>Y$

HOW MANY STATIONS TO BE CHANGED?

$>2$

ENTER STATION NUMBERS TO BE CHANGED -.- N,N,N...

$>1,3$

THERE ARE CURRENTLY 22 STATIONS WITH 2 DISABLED

(Station list is repeated; status of PROS and ARMY is now 1)

ANY CHANGES TO STATUS FLAGS? Y OR N

$>\mathrm{N}$

ANY STATIONS TO BE ADDED? Y OR $N$

$>Y$

HOW MANY STATIONS TO BE ADDED?

$>3$

EACH STATION SPECIFICATION MUST INCLUDE:

STATION ID - 4 CHARACTERS

$X$ AND $Y$ DISTANCES IN KILOMETERS FROM HMS

SPECIFY 4 CHARACTER NAME FOR STATION 1

$>X Y Z 1$

SPECIFY $X$ AND $Y$ DISTANCES FOR STATION 1

$>134,-5.80$ 
(The last two prompts will be repeated for each station to be added. Illegal entries, e.g., letters, blanks, etc., will cause a prompt to repeat)

STRAY: STATION ARRAY SET UP FOR EACH GRID POINT

\section{ACTIVE STATIONS}

(This message indicates that the final wind station changes have been completed)

INTERPOLATION RADIUS IS 5.0 GRID UNITS

DO YOU WANT TO CHANGE THE RADIUS? Y OR N

$>\mathrm{N}$

$\star \star E N D$ GRID INITIALIZATION**

PAUSE HIT RETURN TO CONTINUE >

MESO- $\rightarrow$ PRIMARY INITIALIZATION

ENTER RUN IDENTIFICATION TITLE OF UP TO $5 \emptyset$ CHARACTERS

$>M E S O$ TEST

ENTER DATE FOR START OF SIMULATION-- MMDDYY

$>060381$

JULIAN DATE $=1541981$

ENTER HOUR FOR START OF SIMULATION

$>6$

METEOROLOGICAL DATA FILE SEARCH--

OBSV FILE POSITIONED AT: DAY 154 HOUR 6 RECORD 1

FORECAST FILE STARTS AT: DAY 155 HOUR 1 RECORD 1

PAUSE HIT RETURN TO CONTINUE >

MESO- $\rightarrow$ RECEPTOR INITIALIZATION

DO YOU WISH TO SET UP RECEPTORS? Y OR N

$>Y$

SPECIFY $X$ AND $Y$ COORDINATES OF RECEPTOR 1 IN KILOMETERS FROM HMS

HIT A TO END INPUT MODE

$>-7.5,-7.5$

SPECIFY $X$ AND $Y$ COORDINATES OF RECEPTOR 2 IN KILOMETERS FROM HMS

HIT A TO END INPUT MODE

$>A$

ENTER RECEPTOR ON AND OFF TIMES IN HOURS (01-24)

$>7,9$

END RECEPTOR INITIALIZATION 
PAUSE HIT RETURN TO CONTINUE >

MESO- $\rightarrow$ RELEASE INITIALIZATION

SPECIFY COORDINATES $(X, Y)$ OF SOURCE IN KILOMETERS FROM HMS

$>-12.5,12.5$

ENTER DATE OF RELEASE----MMDDOYY

$>060381$

HOUR OF RELEASE? 1-24

$>6$

MINUTE OF RELEASE? $\quad 0-59$

$>0$

DURATION OF RELEASE? HOURS, MINUTES IF CONTINUOUS ENTER $C$ $>1,30$

9 PUFFS WILL BE RELEASED

IS THE SOURCE TERM KNOWN? Y OR N

$>\mathrm{N}$

At this time, initialization is complete and simulation begins on an hourly basis. At the end of each hour the following information is displayed:

END OF SIMULATION HOUR 1 DATA: DAY 154 HOUR 6

6 PUFFS ACTIVE

SELECT OUTPUT OPTION FOR THIS HOUR- $\rightarrow$

$O=$ NO OUTPUT

$1=$ SCREEN ONLY

$2=$ PRINT FILE ONLY

$3=$ SCREEN AND PRINT FILE

4 = TERMINATE CURRENT SIMULATION

$>$

The user must select from this menu after each hour. The screen display shown gives a simple plot of the integrated concentrations (CHI array) using the numerical symbols below as a key. The $X$ indicates the location of the source and $M$ denotes the location of the meteorological tower. 


\begin{tabular}{cc}
$\begin{array}{c}\text { Integrated } \\
\text { concentration }\end{array}$ & Symbol Displayed \\
\hline$x<1.0 \mathrm{E}-17$ & blank \\
$1.0 \mathrm{E}-17 \leq x<1.0 \mathrm{E}-16$ & 0 \\
$1.0 \mathrm{E}-16 \leq x<1.0 \mathrm{E}-15$ & 1 \\
$1.0 \mathrm{E}-15 \leq x<1.0 \mathrm{E}-14$ & 2 \\
$1.0 \mathrm{E}-14 \leq x<1.0 \mathrm{E}-13$ & 3 \\
$1.0 \mathrm{E}-13 \leq x<1.0 \mathrm{E}-12$ & 4 \\
$1.0 \mathrm{E}-12 \leq x<1.0 \mathrm{E}-11$ & 5 \\
$1.0 \mathrm{E}-11 \leq x<1.0 \mathrm{E}-10$ & 6 \\
$1.0 \mathrm{E}-10 \leq x<1.0 \mathrm{E}-9$ & 7 \\
$1.0 \mathrm{E}-9 \leq x<1.0 \mathrm{E}-8$ & 8 \\
$1.0 \mathrm{E}-8 \leq x<1.0 \mathrm{E}-7$ & 9 \\
$1.0 \mathrm{E}-7 \geq x$ & +
\end{tabular}

Example:

$\begin{array}{lll}\text { MESO TEST (title) } & 090181 \text { (current date) } & 073041 \text { (current time) } \\ \text { SIMULATION HOUR 1 } & \text { DAY } 154 & \text { HOUR } 6\end{array}$

6 PUFFS ACTIVE

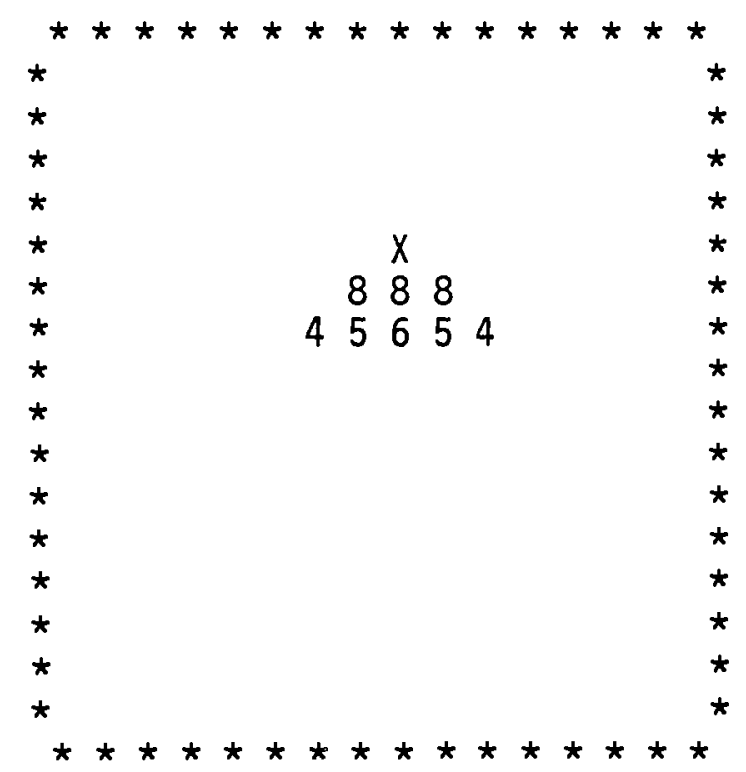

PAUSE HIT RETURN TO CONTINUE >

When no further simulation is desired, terminate the session by selecting output option 4 . The following message/response sequence will then occur: 
END OF SIMULATION

MESO TERMINATED BY USER PRIOR TO 48 HOUR MAX

DO YOU WISH TO RESTART? Y OR N

$>\mathrm{N}$

STOP END MESOI EXECUTION--ADD END FILE

Control has now been returned to the UNIVAC system. Any further simulation must begin with an $\mathrm{ADDD}$ . command.

If a response of ' $Y$ ' is given to the restart query, the system responds with: DO YOU WISH TO REINITIALIZE THE GRID? Y OR N

A response of ' $Y$ ' returns the program to the beginning of the grid initialization. Any other response returns the program to the primary model initialization, skipping the grid initialization. Execution continues using the grid specifications of the previous run. 


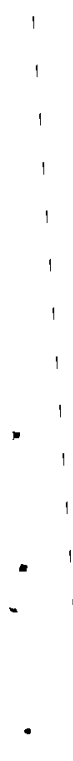




\section{PRACTICE SESSIONS WITH MESOI}

There are four data files and command groups available for use in testing the model or for use in practice sessions. Each group consists of a meteorological data file, a forecast data file, a start execution file, and a termination file. The characteristics of each group are summarized below.

1. A very simple data set with spatially uniform and temporally constant conditions

$$
\text { stability }=6
$$

mixing level $=400$ meters

wind direction $=0^{\circ}$

wind speed $=5 \mathrm{mph}$

Observed and forecast data files are identical: 48 hours of data beginning at hour 01 on 3 June, 1981.

Data file names: MDATAl. FDATAl.

Execution and termination file names: EXPGO1. EXPND1.

2. A simple data set that uses both the observed and forecast data files.

$$
\begin{aligned}
& \text { stability }=4 \\
& \text { mixing level }=2000 \text { meters } \\
& \text { wind direction }=315^{\circ} \\
& \text { wind speed }=10 \mathrm{mph}
\end{aligned}
$$

The observed data file begins at hour 01 on 3 June, 1981. After 36 hours, the day is set to $=888$ to indicate no further observations. The forecast file begins at hour 01 on day 4 June 1981 and contains 48 hours of the described data.

Data file names: MDATA2. FDATA2.

Execution and termination file names: EXPG02. EXPND2.

3. A data set similar to number 2, except the wind direction shifts $90^{\circ}$ after 24 hours.

$$
\begin{aligned}
& \text { stability }=4 \\
& \text { mixing level }=200 \text { meters } \\
& \text { wind speed }=7 \mathrm{mph} \\
& \text { wind direction }=315^{\circ} \text { during } 1 \text { st } 24 \text { hours } \\
& =225^{\circ} \text { during } 2 \text { nd } 24 \text { hours } \text {. }
\end{aligned}
$$


Observed and forecast data files are identical; 48 hours beginning at hour 01 on 29 July, 1981.

Data file names: MDATA3. FDATA3.

Execution and termination file names: EXPG03. EXPND3.

4. A data set with 48 hours of actual meteorological observations. Observed and forecast data files are identical; beginning at hour 01 on 15 December, 1978.

Data file names: MDATA4. FDATA4.

Execution and termination file names: EXPG04. EXPND4.

The sample display presentation shown in the previous section was obtained using the first practice data set. Sample simulations have been completed with the remaining three practice data sets. In each of the simulations the default wind grid was used, and the data sets were used without modification. Table 1 gives the values of the variable parameters used in each simulation. Terminal display presentations at selected times in the simulations are shown to provide users with a means for rapidly checking their results.

\section{TABLE 1. MESOI Control Parameter Values for Practice Runs}

$\begin{array}{llll}\text { Data Set } & 2 & 3 & 4 \\ \text { Starting Date } & 060381 & 072981 & 121578 \\ \text { Starting Time } & 01 & 22 & 01 \\ \text { Off-grid Receptors } & \mathrm{N} & \mathrm{Y} & \mathrm{Y} \\ & & -15.25, .25 & -20.25,20.25 \\ & & -25 .-.25 & 20.25,20.25 \\ & & 10.25,10.25 & -20.25,-20.25 \\ & & 20.25,-20.25 \\ \text { Receptor Times (On/0ff) } & 22 / 03 & 01 / 06 \\ \text { Source Point } & -20.25,20.25 & -25.25,10.25 & -1.0,1.0 \\ \text { Release Date } & 060381 & 072981 & 121578 \\ \text { Release Hour } & 01 & 22 & 01 \\ \text { Release Minute } & 0 & 0 & 30 \\ \text { Duration of Release } & 1,0 & \mathrm{C} & 3,30 \\ \text { Source Term } & \mathrm{N} & \mathrm{N} & \mathrm{N} \\ \text { Time of Output } & 3 & 3,6 & 6 \\ \text { (Simulation hours) } & & & \end{array}$


1. Practice data set 2 , Simulation hour 3

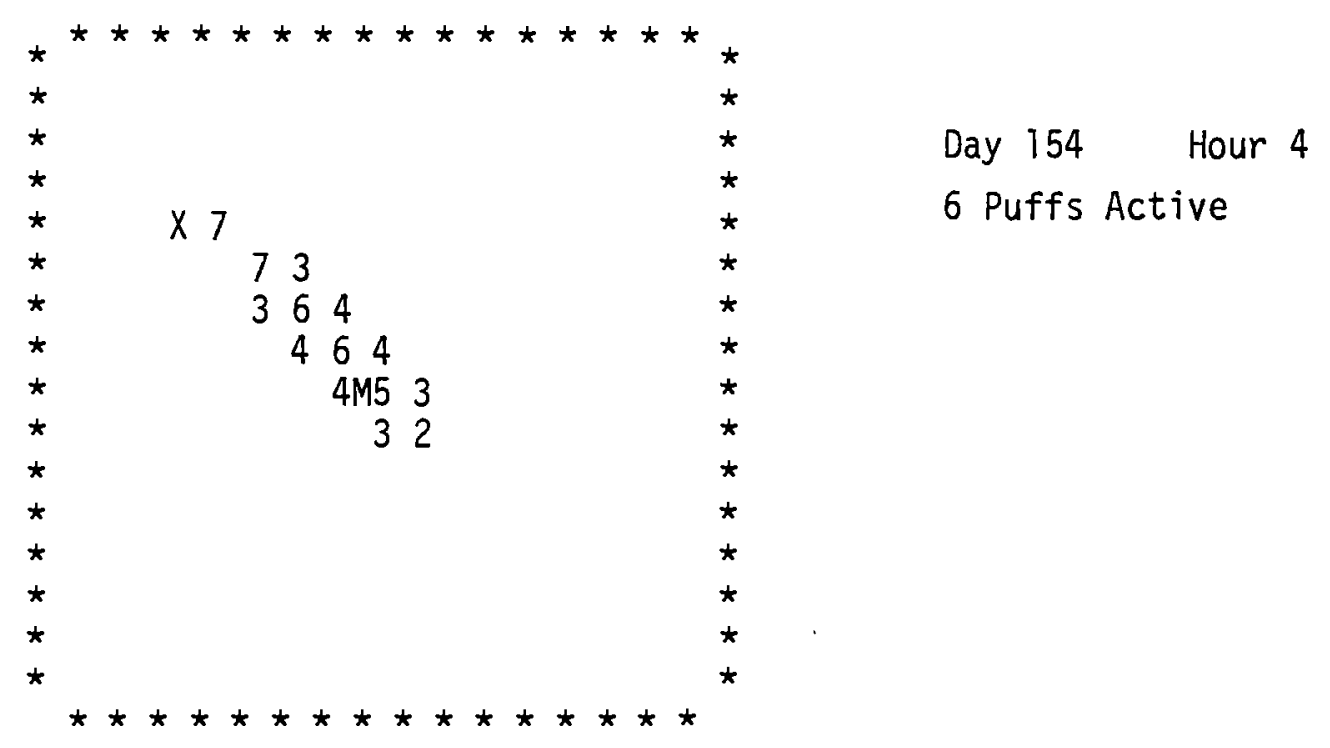

2. Practice Data Set 3 , Simulation Hour 3

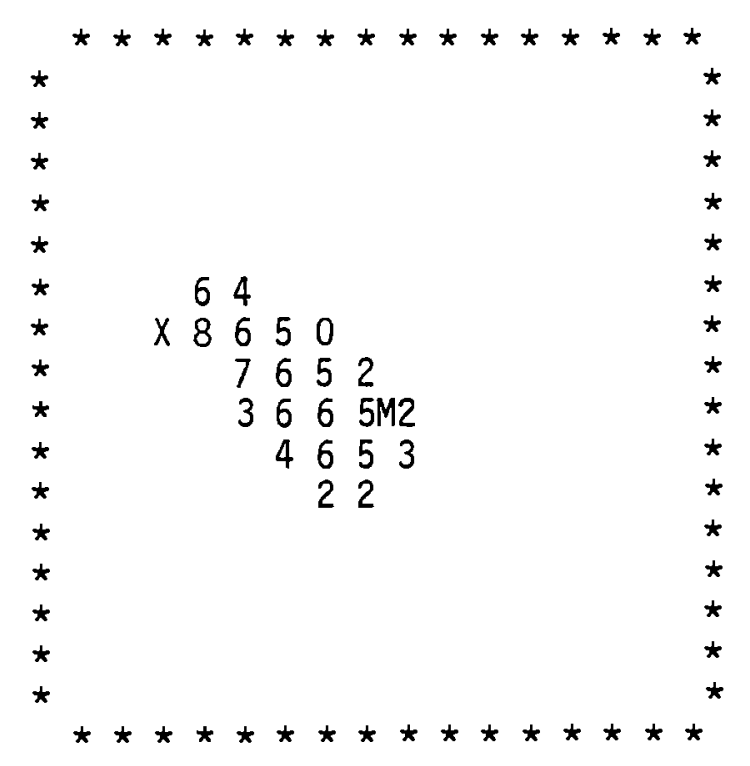

Day 211 Hour 1

18 Puffs Active 
3. Practice Data Set 3, Simulation Hour 6

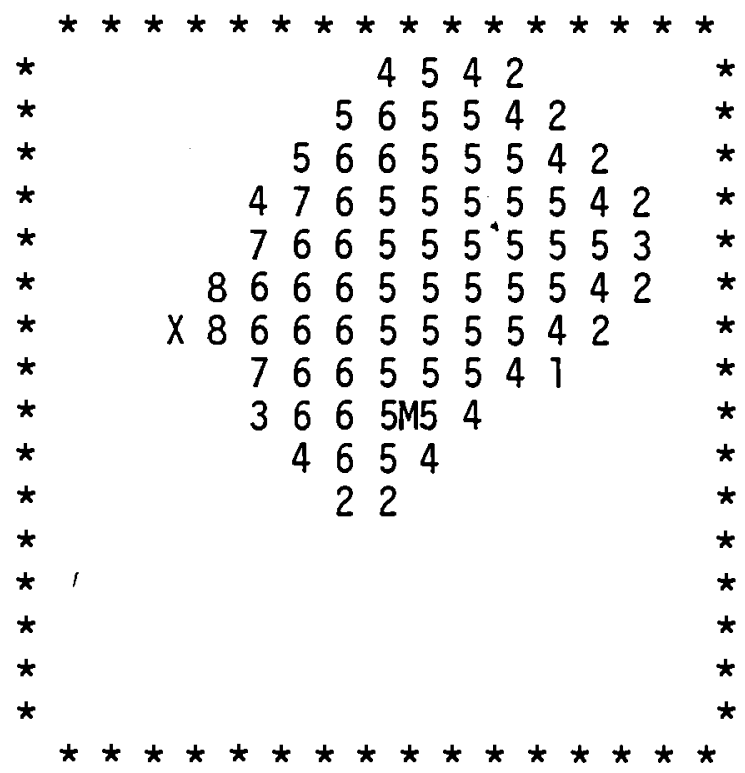

Day 211 Hour 4

36 Puffs Active

The exposures at the off-grid receptors at the end of their sampling period were: Receptor 1 -- $9.41 \mathrm{E}-11 \mathrm{hr} / \mathrm{m}^{3}$, Receptor 2 --- $8.01 \mathrm{E}-12 \mathrm{hr} / \mathrm{m}^{3}$, and Receptor 3 -.- $5.73 \mathrm{E}-12 \mathrm{hr} / \mathrm{m}^{3}$.

4. Practice Data Set 4, Simulation Hour 6.

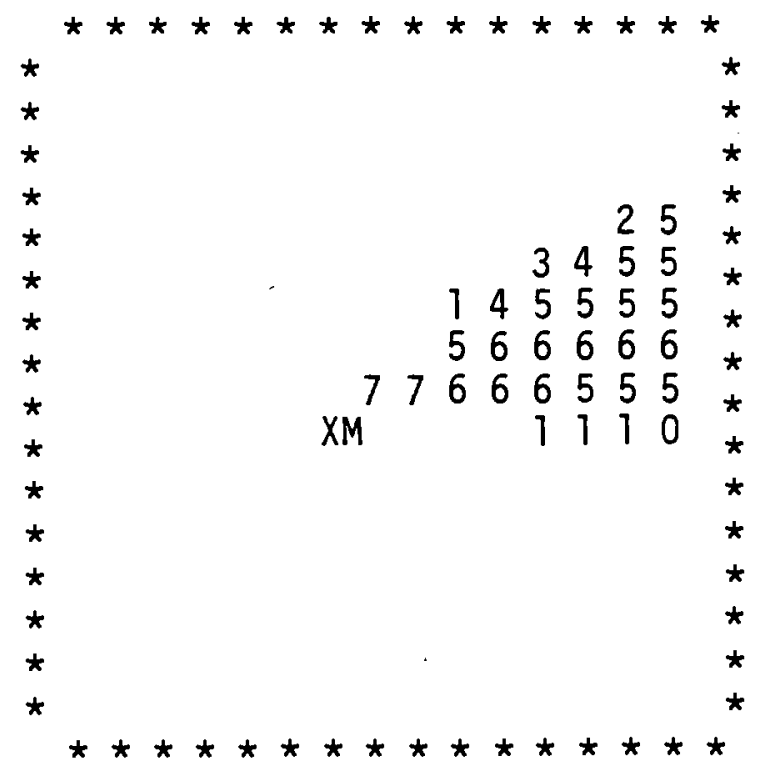

Day 349 Hour 7

0 Puffs Active

The exposures at all off-grid receptors were less than $10^{-17} \mathrm{hr} / \mathrm{m}^{3}$. 


\section{UPDATE AND LOGRVU USE}

UPDATE is an interactive computer program used for building, reviewing and modifying the observation and forecast data files called by MESOI. Each file contains up to 48 hours of stability, mixing height and wind data.

Meteorological observations are entered into the observation file as they become available. Up to 48 hours of observations can be maintained in the file. The first observation in the file is always hour 1 of day 1 and the 25 th observation is hour 1 of day 2. Upon entry of the 49th observation, the first day's data are written to a backup disk file named ARCHIV. A batch job is automatically submitted under the name ARCHUP. to update the archived data files. The first 24 hours of data are then dropped from the active observed data file and are replaced by the second day's data, and the new observation will then be entered as the 25 th observation in the file (2nd day, 1st hour). Subsequent observations will be entered as observations 26 through 48 until another day is complete, at which time the cycle will repeat. Twenty-five hours of observed data will always be maintained on the file. Data will continue to accumulate in the archive file until deleted.

The forecast data file contains 48 hours of forecast stability, mixing height and wind data. This file can start at any hour of the day. For example, a forecast file starting at hour 9 on July 25 will end on hour 8 on July 27 (48 hours). Forty-eight hours of forecast data will always be maintained in file.

UPDATE is a highly user-oriented computer program installed on a UNIVAC 1100 system. Once the user starts UPDATE all that is necessary is to answer questions with "Y" (Yes) or "N" (No) and enter the appropriate meteorological data. The date and time, user ID and type of activity, i.e., "New Obs", "Rev Obs", "New Fcst" or "Rev Fcst", are automatically recorded in the appropriate $\log$ file. These files can be reviewed by running the program LOGRVU.

The logic flow chart for program UPDATE is given in Figure 2. Upon starting the program the user is asked to enter a user identification (e.g., user's last name). After this the user is asked "DO YOU WISH TO ENTER OR REVISE 


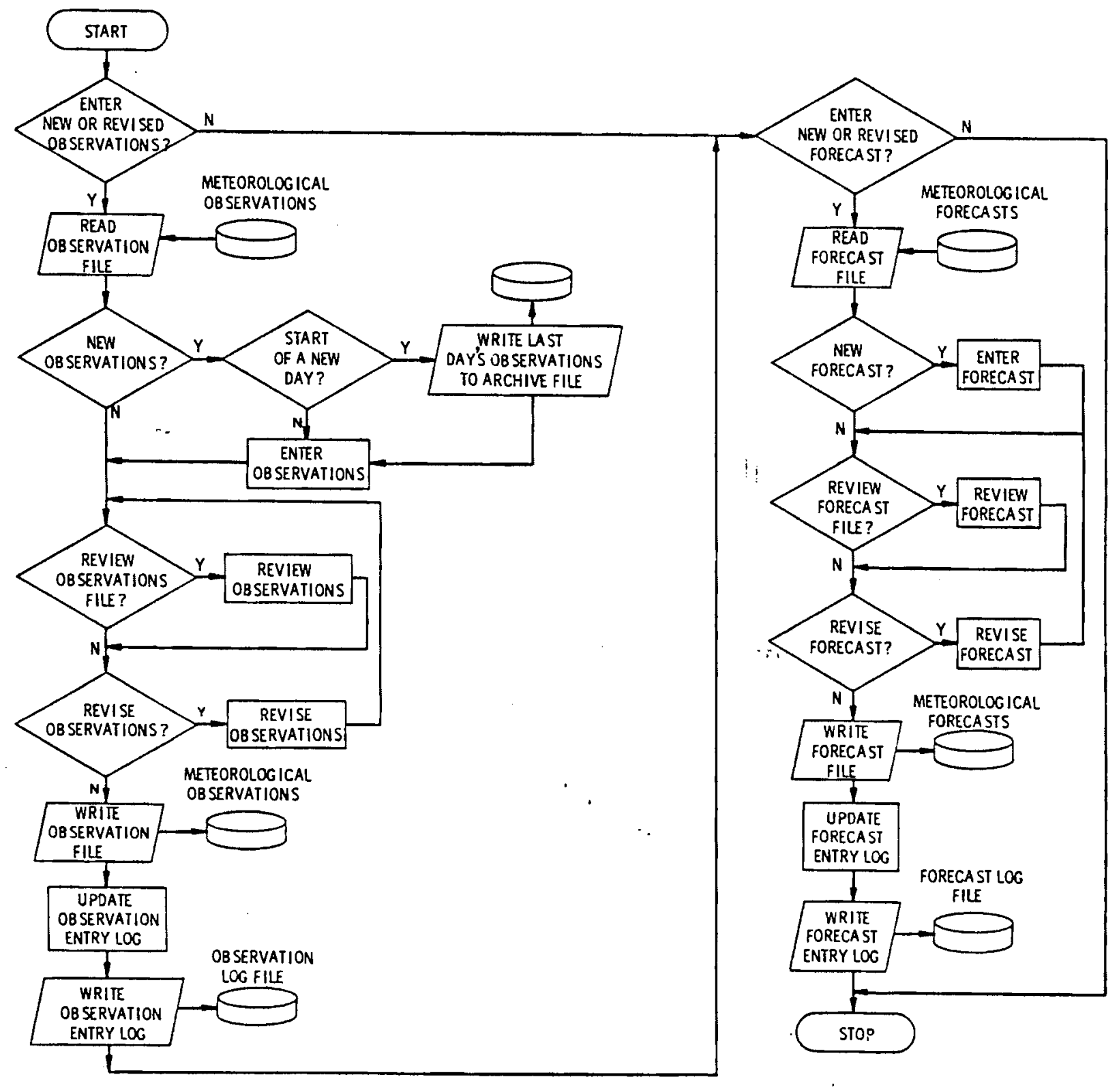

FIGURE 2. UPDATE Flow Chart 
OBSERVED DATA?". If the answer is 'no', the program goes to the forecast half of the program. If the answer is 'yes', the question "DO YOU WISH TO ENTER A NEW SET OF OBSERVATIONS?" is displayed. A 'yes' causes control to pass to the new observation entry portion of the program. After entry of the new data, the user has the opportunity to review and revise the contents of the observed data file. The contents of the observed data file may also be reviewed and revised without initially entering a new set of observations. If revisions are made, the user is given the option to review the data at the completion of the revision session. This process of revise-review can occur as many times as the user wishes.

When the user no longer wishes to review or revise entries in the observed data file control passes to the forecast half of the program. The program logic in the forecast half is identical to the logic in the observation half.

In either the observation or the forecast portion of the program, once control is passed from the "NEW" entries section, it cannot be accessed again. Additional new entries can be made by simply rerunning the UPDATE program.

The user's guide to UPDATE and LOGRVU is divided into two sections. The first describes the command sequences required to gain access to the UNIVAC computer, initiate program execution and disconnect the computer at the end of the session. Much of the material in this section is a review of information presented earlier. The second section of the guide is an example of the sequence of prompts and responses in a typical interactive session. The computer codes for UPDATE and LOGRVU are presented in Appendix A.

\section{UNIVAC CONTROL SEQUENCES FOR UPDATE AND LOGRVU}

The control sequence to gain access to the UNIVAC for a session with UPDATE or LOGRVU is the same as the sequence used for MESOI with the exception of the QADD command. The sequence is reviewed here. The proper CADD commands are given for normal use of the programs and for use with practice files. 


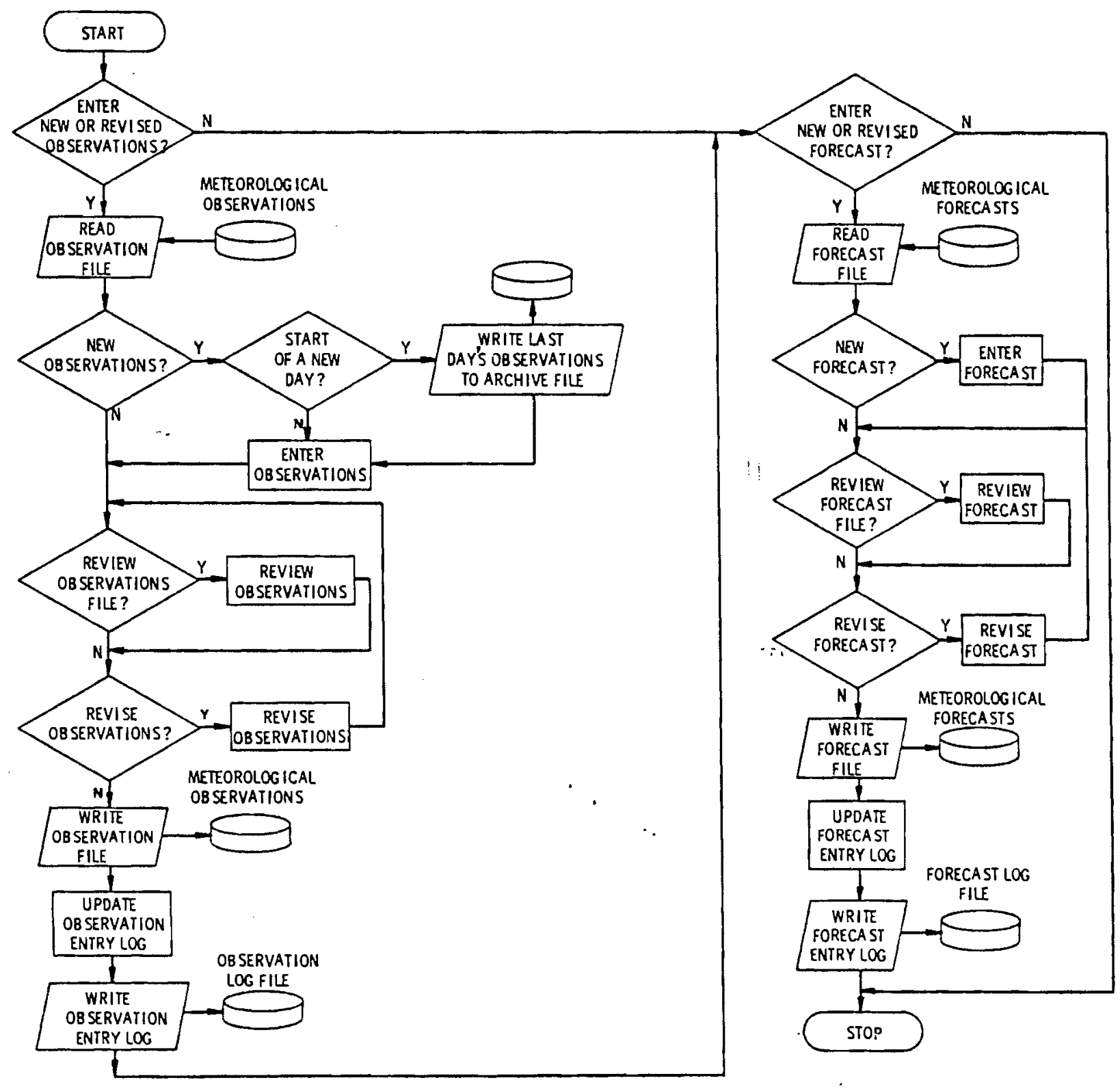

FIGURE 2. UPDATE Flow Chart 


\section{Starting Program Execution}

To start the programs it is necessary to assign the data files and give an execute command. This can be accomplished with the following sequence. The first is for routine use, and the second is for practice.

1. Complete the login procedure

2. Key in:

QADD UT. $\langle C R>$

3. To rUn UPDATE, key in:

$$
\text { QXQT MESOUT.UPDATE <CR> }
$$

To run LOGRVU, key in:

QXQT MESOUT. LOGRVU <CR>

UPDATE and LOGRVU can be run any number of times by simply re-entering steps $(A)$ and $(B)$.

4. Complete the logout procedure.

Dummy observation, forecast and log files (MDATAP., FDATAP., MDLP., FDLP.) have been set up so the user can practice using UPDATE and LOGVU without disturbing the working observation and forecast files.

These practice files are made available by using the following procedure:

1. Complete login

2. Key in:

QADD UTPRA. $\angle C R>$; system resonds with 8 READY messages

3. To rUn UPDATE, key in:

QXQT MESOUT.UPDATE 〈CR>

To rUn LOGRVU, key in:

QXQT MESOUT. LOGRVU <CR>

UPDATE and LOGRVU can be run any number of times by simply re-entering steps $(A)$ or $(B)$.

Complete logout procedure. 


\section{Logout Procedure}

The procedure for disconnecting the terminal is the same for UPDATE and LOGVU as it was for MESOI. The sequence of commands is repeated here for completeness.

Key in

OOSKIP $20<C R>$ (to avoid the summary listing of terminal session charges) QFIN $\angle C R>\quad$ (deactivates terminal) OOTERM $<C R>$ (terminates the communication link)

INTERACTIVE SESSIONS WITH UPDATE AND LOGRVU

The use of the interactive utility UPDATE and LOGRVU programs is straightforward. It involves yes and no answers to control program options and entering data when requested. As in MESOI, $Y$ and $N$ can be substituted for yes and no. Entering, Reviewing and Revising Observations

In order to demonstrate the use of UPDATE a step by step example is presented below. The example consists of entering new observations for one hour, reviewing the observations and correcting one entry. The data to be entered are:

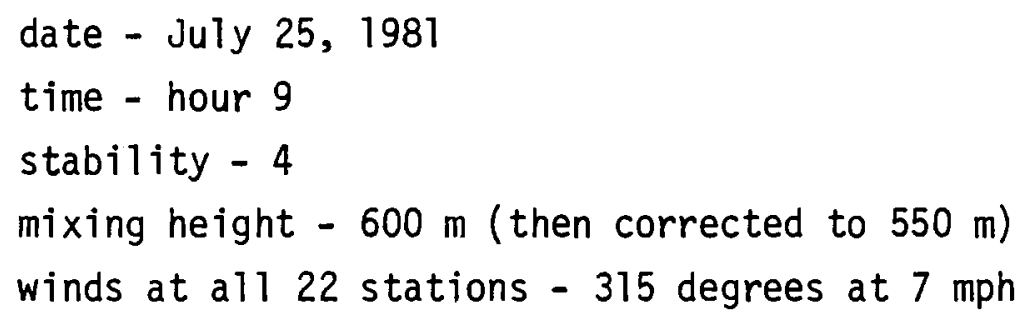

It is assumed that the existing observed data file is complete up to hour 8 of Ju1y 25,1981 .

The following sequence traces the computer requests and corresponding user responses once the execution of UPDATE has started. The user responses are to the left of the computer prompt symbol ">". All user entered values must be followed by pushing the console RETURN key. The RETURN, though, will be omitted for simplicity. 
MESOUT VERSION $1.0 \quad$ OCTOBER 1987

ENTER USER IDENTIFICATION. USE A MAXIMUM OF 8 CHARACTERS

$>$ JONES

METEOROLOGICAL DATA ENTRY PROGRAM FOR MESOI

DO YOU WISH TO ENTER OR REVIEW OBSERVED DATA? ENTER Y OR N

$>Y$

ENTER YEAR OF OBSERVATION TO BE ENTERED:YY

$>81$

THE MONTH, DAY AND HOUR OF THE LAST OBSERVATION ENTERED ARE: 7258 .

THE NEW ENTRIES MUST FOLLOW THIS TIME.

ENTER MONTH AND DAY OF OBSERVATION TO BE ENTERED: MM,DD (E.G. - 7,25).

$>7,25$

ENTER HOUR OF THE OBSERVATION:HH

$>9$

THE DATE AND HOUR FOR OBSERVATION TO BE ENTERED ARE; 725819

ARE THESE CORRECT? ENTER Y OR N.

$>Y$

THE JULIAN DATE OF THE DATA IS 206

ENTER STABILITY CLASS: 1 THROUGH 7.

$>4$

ENTER MIXING DEPTH IN TENS OF METERS:

1 THRU 300.

$>60$

ENTER WIND DATA AS DDDFF, WITH 00000=CALM and 99999=MISSING.

DO NOT USE LT/VAR, USE CALM, OR ESTIMATE THE AVERAGE SPEED AND DIRECTION.

ENTER WIND FOR PROS BAR

$>37507$

ENTER WIND FOR ARMY LPR

$>31507$

(and so on for the other stations.) 
DO YOU WISH TO ENTER OBSERVATIONS FOR ANOTHER TIME?

$>\mathrm{N}$

DO YOU WISH TO REVIEW THE OBSERVED DATA FILE

$>Y$

DO YOU WISH TO REVIEW THE ENTIRE OBSERVED DATA FILE?

$>\mathrm{N}$

DO YOU WISH TO REVIEW DATA FOR SPECIFIC HOURS?

$>Y$

ENTER DATE OF DATA TO BE REVIEWED: MM,DD, YY

$>7,25,81$

ENTER HOUR OF THE DATA TO BE REVIEWED: $H H$

$>9$

DATA ARE DISPLAYED IN THE FOLLOWING ORDER:

JULIAN DATE, HOUR, STABILITY, MIXING DEPTH, WINDS.

THE ORDER OF THE WIND DATA IS:

PROS BAR EM RE CE ARMY LPR RATT SPR EDNA 200E

200W WAHL SLP FFTF YAK BARR 300 AREA WYE BARR

100N WPPSS FRANK CO GABLE MO RINGOLD RICH AP

SAGEHILL RATT MTN HA MT ST PASCO

"206 94 603150731507315073150731507315073150731507

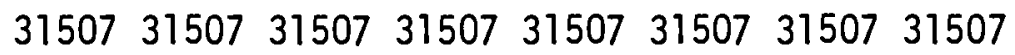

$315073150731507315073150731507 "$

TYPE $N<C R>F O R$ NEXT RECORD OR JUST <CR> TO EXIT

DO YOU WISH TO REVIEW ADDITIONAL HOURS?

$>\mathrm{N}$

DO YOU WISH TO REVISE ANY DATA ENTRIES?

$>Y$

ENTER DATE OF OBSERVATION TO BE REVISED: MM,DD,YY.

$>7,25,81$

THE JULIAN DATE FOR THE REVISION IS 206

ENTER HOUR OF THE OBSERVATION TO BE REVISED: HH.

A 99 CAN BE USED TO ESCAPE FROM THE DATA REVISION SUBROUTINE 


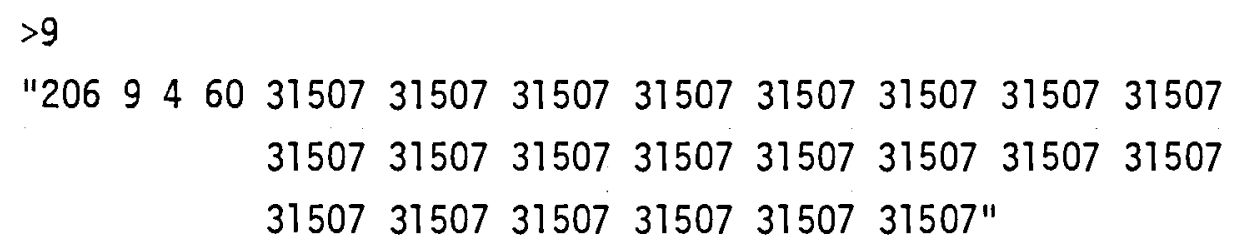
responding to a series of questions. 
Entering, Reviewing and Revising Forecasts

The following example demonstrates entering, reviewing and revising forecast data. The forecast starts with hour 10 of July 25, 1981 and ends at hour 9 of July $27,1981$.

The forecast is:

period - 1000 through 1600 July 25.

stability - 3

mixing height - $1000 \mathrm{~m}$.

winds at all stations -315 at 7 .

period - 1700 July 25 through 0900 July 27

stability -4

mixing height - $500 \mathrm{~m}$

winds at all stations -270 at 10.

The revision to be entered is:

period - 1500 July 25 through 400 July 26

stability - 5 .

mixing height - $300 \mathrm{~m}$

winds at all stations - no change.

The following sequence traces the computer requests and corresponding user responses for the example. The user responses are to the left of the computer prompt symbol ">". All user entered values must be followed by pushing the console RETURN key. The RETURN, though, will be omitted for simplicity.

MESOUT VERSION 1.0 OCTOBER 1981

ENTER USER IDENTIFICATION. USE A MAXIMUM OF 8 CHARACTERS.

$>$ JONES

METEOROLOGICAL DATA ENTRY PROGRAM FOR MESOI

DO YOU WISH TO ENTER OR REVISE OBSERVED DATA?

$>N$

DO YOU WISH TO ENTER A NEW FORECAST?

$>Y$ 
ENTER START DATE OF NEW FORECAST: MM,DD, YY

(E.G. - 7, 29, 81).

$>7,25,81$

ENTER START HOUR OF NEW FORECAST: HH.

$>10$

THE JULIAN DATE OF THE FORECAST IS 206.

ENTER STABILITY CLASS: 1 THROUGH 7.

$>3$

ENTER MIXING DEPTH IN TENS OF METERS:

1 THRU 300.

$>100$

ENTER WIND FCST AS DDDFF, WITH 00000=CALM AND $99999=M I S S I N G$.

DO NOT USE LT/VAR, USE CALM OR ESTIMATE THE AVERAGE SPEED AND

DIRECTION. ENTER WIND FOR PROS BAR

$>31507$

ENTER WIND FOR EM RE CE

$>31507$

ENTER WIND FOR ARMY LPR

$>31507$

(and so on for the other stations.)

DO YOU WISH TO ENTER FORECASTS FOR ANOTHER TIME?

$>Y$

ENTER DATE OF FORECASTS TO BE ENTERED: MM, DD, YY

$>7,25,81$

ENTER HOUR OF THE FORECAST: HH

$>17$

THE JULIAN DATE OF THE FCST IS 206.

THE CURRENT STABILITY FCST IS 3 DO YOU WISH TO

REVISE THE FCST?

$>Y$

ENTER STABILITY CLASS: 1 THROUGH 7.

$>4$ 
THE CURRENT MIXING DEPTH FCST IS 100. DO YOU WISH TO REVISE THE FCST? $>Y$

ENTER MIXING DEPTH IN TENS OF METERS:

1 THRU 300.

$>50$

ENTER WIND FCST AS DDDFF, WITH 00000=CALM. AND 99999=MISSING

DO NOT USE LT/VAR, USE CALM OR ESTIMATE THE AVERAGE SPEED

AND DIRECTION. THE CURRENT WIND FCST FOR PROS BAR IS 31507.

DO YOU WISH TO CHANGE IT?

$>Y$

ENTER WIND FOR PROS BAR

$>27010$

(and so on for all wind stations.)

DO YOU WISH TO ENTER FORECASTS FOR ANOTHER TIME?

$>\mathrm{N}$

DO YOU WISH TO REVIEW THE CURRENT FORECAST?

$>Y$

DO YOU WISH FO REVIEW THE ENTIRE FORECAST DATA FILE?

$>Y$

THE FORECAST FILE WILL BE DISPLAYED IN 6 HOUR BLOCKS.

HITTING RETURN WILL DISPLAY THE NEXT BLOCK. THE FORECAST

ORDER IS: JULIAN DATE, HOUR, STABILITY, MIXING DEPTH, WINDS. THE WIND STATION ORDER IS:

PROS BAR EM RE CE ARMY LPR RATT SPR EDNA 200E

200W WAHL SLP FFTF YAK BARR 300 AREA WYE BARR

100N WPPSS FRANK CO GABLE MO RINGOLD RICH AP

SAGEHILL RATT MTN HA MT ST PASCO

2061031003150731507315073150731507315073150731507

$\begin{array}{lllllllll}31507 & 31507 & 31507 & 31507 & 31507 & 31507 & 31507 & 31507\end{array}$

315073150731507315073150731507 
$206113100315073150731507 \quad--$

$3150731507 \quad-.-$

31507 -.-

$20612310031507 \quad---$

(and so on through 6 hours of data.)

TYPE N $<C R>$ FOR NEXT BLOCK OR JUST $<C R>$ TO EXIT

$>\langle\mathrm{CR}\rangle$

DO YOU WISH TO REVIEW FORECASTS FOR SPECIFIC HOURS?

$>\mathrm{N}$

DO YOU WISH TO REVISE THE FORECAST?

$>Y$

ENTER DATE OF FORECAST TO BE REVISED: MM,DD, YY

$>7,25,81$

THE JULIAN DATE FOR THE REVISION IS 206

ENTER HOUR OF THE FORECAST TO BE REVISED: HH.

A 99 CAN BE USED TO ESCAPE FROM THE FCST REVISION SUBROUTINE

$>15$

ENTER FORECAST PERSISTENCE: HH ( 1 to 48 ).

$>14$

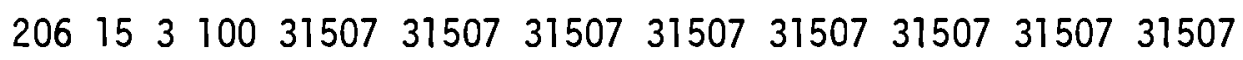

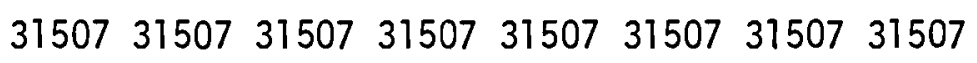

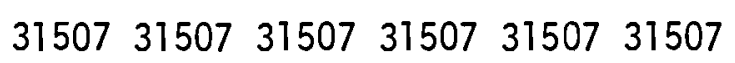

IS THIS THE RECORD TO REVISE? Y OR N

$>Y$

REVISION TO WIND DATA ONLY? Y OR N

$>\mathrm{N}$

DO YOU WISH TO REVISE THE STABILITY?

$>Y$

ENTER REVISED STABILITY: 1 THROUGH 7. $>5$ 
DO YOU WISH TO REVISE THE MIXING DEPTH?

$>Y$

ENTER REVISED MIXING DEPTH IN TENS OF METERS:

1 THRU 300.

$>30$

DO YOU WISH TO REVISE WIND FCSTS?

$>\mathrm{N}$

DO YOU WISH TO ENTER MORE REVISIONS?

$>\mathrm{N}$

DO YOU WISH TO REVIEW THE CURRENT FORECAST?

$>\mathrm{N}$

THIS UPDATE SESSION IS OVER.

When entering a new forecast the complete 48 hour period is filled with the initial entry. Each follow-on entry will fill the forecast from the hour of the forecast to the end of the forecast period. Any revision to the forecast will cause all the data, between the revision start hour and start hour plus hours of persistence, to be set to that specified in the revision.

Reviewing Activity Logs

The observation and forecast activity logs can be reviewed by running program LOGRVU. These log files contain information on when, by whom and for what reason the observation or forecast data files were accessed. Upon execution of LOGRVU the question DO YOU WISH TO HAVE THE LOGS PRINTED IN ADDITION TO BEING DISPLAYED? will come across the screen. A yes will direct the logs to the printer, a no will simply continue with the console display of the logs. The next question will be DO YOU WISH TO REVIEW THE DATA ENTRY LOGS? A yes response will cause the log to be displayed on the console screen plus printed (if the answer to the first question was yes). A no will cause the observation log to be bypassed with the program then asking DO YOU WISH TO REVIEW THE FORECAST ENTRY LOG?. Yes or no responses will have the same consequences as with the observation file. The program execution terminates after the forecast log review. A final message THIS LOG REVIEW SESSION IS OVER is displayed. 


\section{REFERENCES}

Ramsde11, J. V. and G. F. Athey, 1981. MESOI: An Interactive Lagrangian Trajectory Puff Diffusion Model. PNL-3998, Pacific Northwest Laboratory, Richland, WA.

Start, G. E. and L. L. Wende11, 1974. Regional Effluent Dispersion Calculations Considering Spatial and Temporal Meteorological Variations, NOAA Tech. Memo., ERL ARL-44, 63 p. 


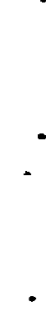




\section{APPENDIX A}

UPDATE AND LOGRVU PROGRAMS 
APPENDIX A

UPDATE AND LOGRVU PROGRAMS

UPDATE and LOGRVU are utility programs to maintain observed and forecast meteorological data files for use by the MESOI diffusion model. UPDATE is used to enter new observations or forecasts and review and revise existing forecasts. It also keeps a record of changes in the data files by recording the time, person making the change and type of change in activity logs. The most recent 48 changes are documented at any time. The activity logs can be examined using the program LOGRVU.

The next section of this Appendix describes the organization of the programs, and the following sections contain listings of these programs.

PROGRAM STRUCTURE, DEFINITIONS AND FILES

UPDATE consists of the main program plus twelve subroutines. The main program MASTER calls subroutines: NUDAT, RVUDAT, REVDAT, NUFCST, RVUFST, REVFST and UPDATL. These seven subroutines, called by MASTER, in return call five subroutines as shown in Table A-1. Program LOGRVU calls no subroutines.

TABLE A-1. Subroutines Called by Main Subroutines in UPDATE

Calling

Subroutine

NUDAT

RVUDAT

REVDAT

NUFCST

RVUFST

REVFST

UPDATL
Called Subroutine

\begin{tabular}{|c|c|c|c|c|}
\hline JULIAN & CAL & INDEX & ADATE & ARCHIV \\
\hline$X$ & $x$ & & & $X$ \\
\hline$X$ & $X$ & & & \\
\hline$X$ & $x$ & & & \\
\hline$X$ & $X$ & $X$ & & \\
\hline$X$ & $x$ & $X$ & & \\
\hline$X$ & $X$ & $X$ & & \\
\hline & & & $X$ & \\
\hline
\end{tabular}


Following are brief descriptions of each subroutine used by UPDATE:

NUDAT Enables the addition of new observations to the observation file. Any number of observations can be added.

RVUDAT Allows the observation file to be reviewed. Any record on the file can be reviewed or the entire file can be reviewed.

REVDAT Allows the observation file to be revised.

NUFCST same as NUDAT only for forecast file.

RVUFST same as RVUDAT only for forecast file

REVFST same as REVDAT only for forecast file. Also a number of hours can be revised at once by specifying the number of hours of persistences.

UPDATL enters date, time, user identification, and activity type to the appropriate log file (either observation or forecast log). The activity types are: New Obs, Rev Obs, New FCST and Rev FCST.

JULIAN converts month, day, year to Julian date 1 through 365 ( 1 through 366 for leap year).

CAL converts Julian date and year to month and day.

INDEX given the Julian date and hour INDEX determines the array index of where the forecast values are to be stored.

ADATE is a system subroutine which returns actual date and time to the program when called.

ARCHIV Writes the last 24 hours of meteorological data to a disk file; called when 1st hourly observation of a new day is entered.

Five disk files are used by UPDATE for input/output. The file names are MDATA, MDL, FDATA, FDL, and ARCHIV. MDATA is the 48 hour observation file assigned to logical unit 10 , MDL is the observation $\log$ file assigned to unit 11 , FDATA is the 48 hour forecast file assigned to unit 12, FDL is the forecast log assigned to unit 13, and ARCHIV is the storage file for observation data after they are deleted from MDATA. Four dummy files are assigned to allow practicing UPDATE and LOGRVU without disturbing the actual working files. These dumm files are MDATAP, MDLP, FDATAP and FDLP. 
Two command files are set up for execution of UPDATE or LOGRVU. The command file named UT assigns the appropriate I/O files when working with the real observation or forecast files. The other command file UTPRA. is set up to assign the dummy files when practicing with UPDATE or LOGRVU. The file contents are:

1. UT.

PASG, A MDATA

QUSE 10, MDATA.

QASG,A MDL.

QUSE 11, MDL.

QASG,A FDATA.

QUSE 12, FDATA.

@ASG,A FDL.

QUSE $13, F D L$.

2. UTPRA.

CASG, A MDATAP.

QUSE 10,MDATAP.

QASG,A MDLP.

OUSE 11, MDLP.

QASG, A FDATAP.

OUSE 12 , FDATAP.

QASG, A FDLP.

QUSE 13, FDLP. 


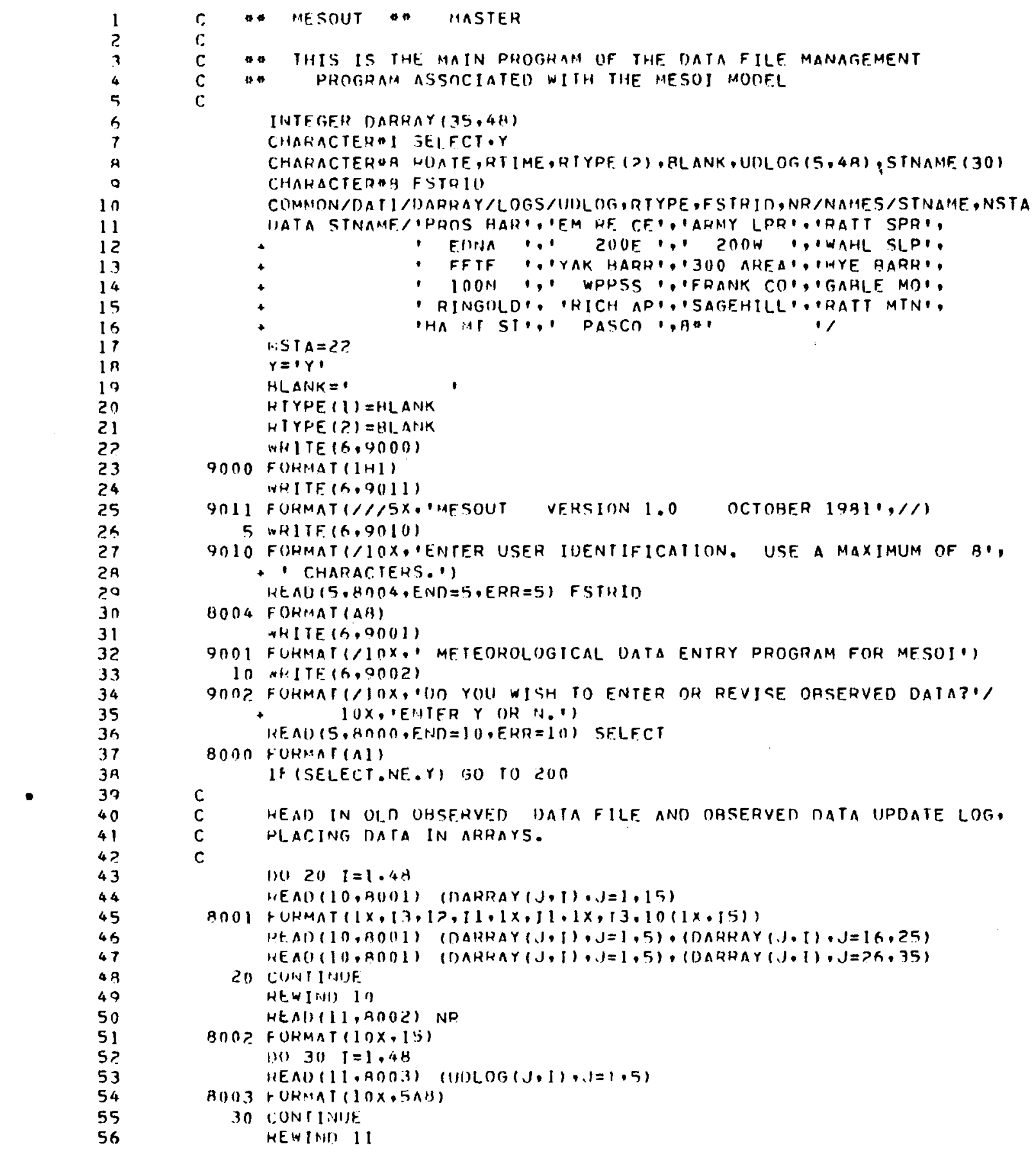

MASTER Program 


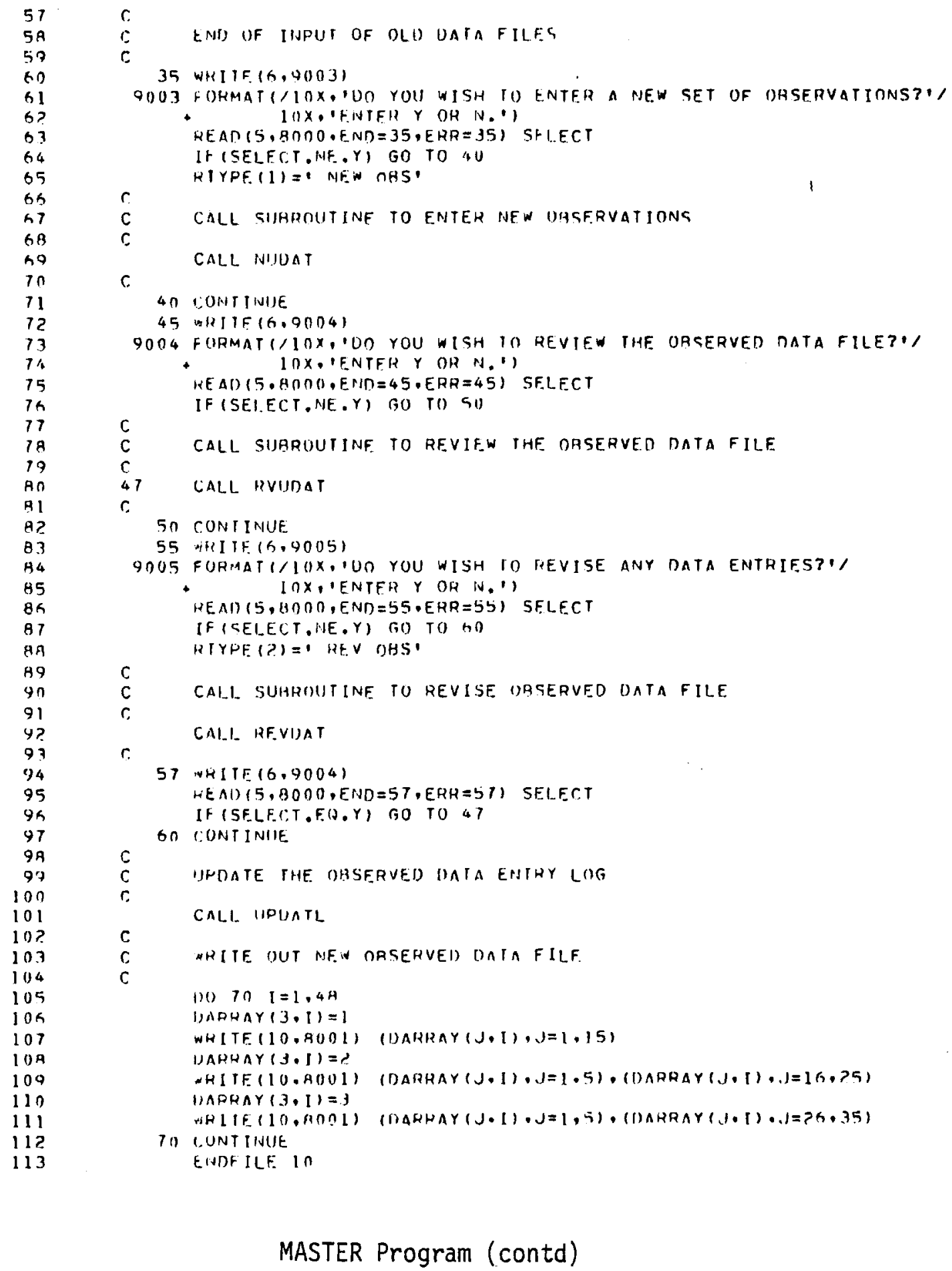




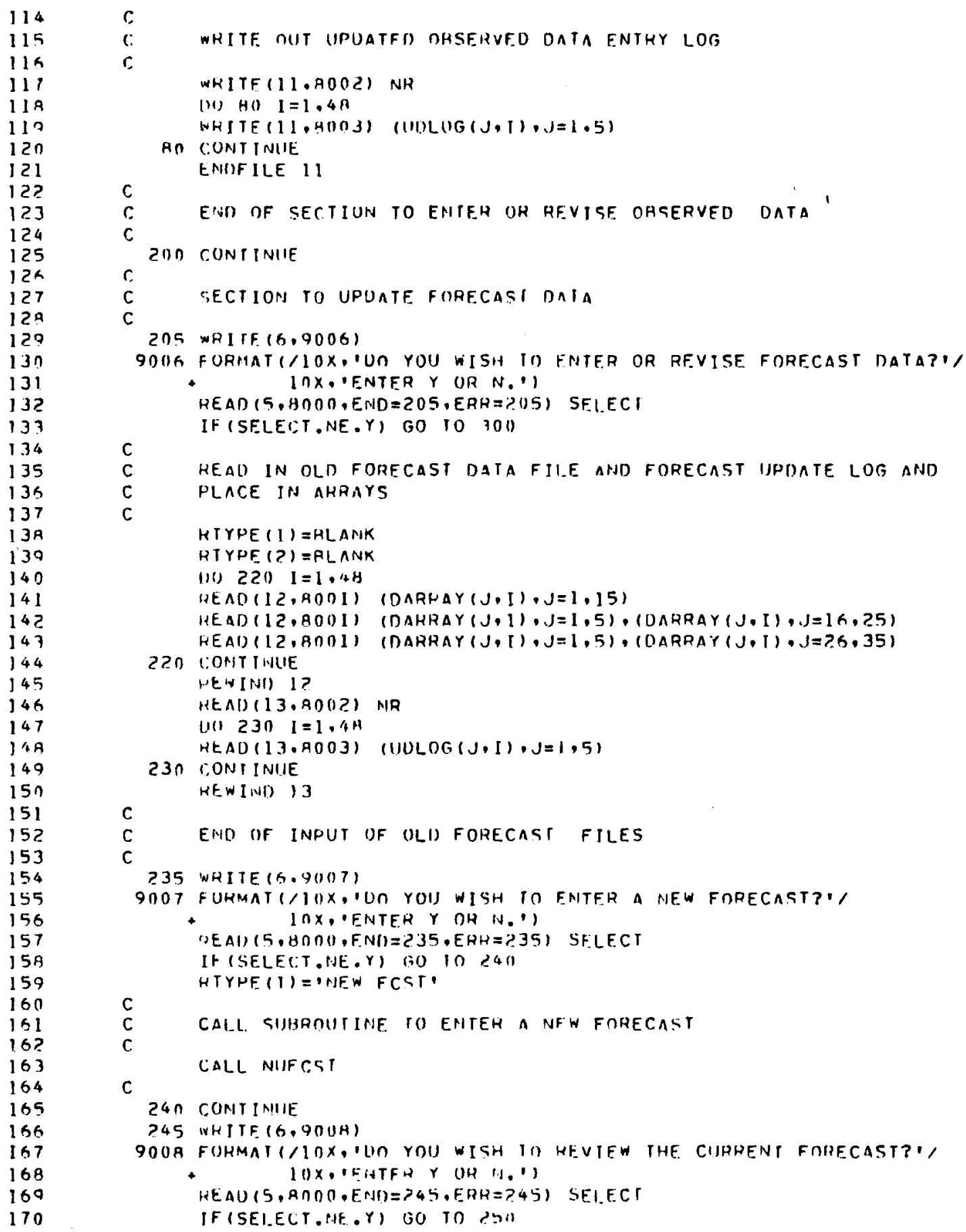

r

C. WITF (11.9002) NH

(ii) $\mathrm{HO} \quad \mathrm{I}=1.4 \mathrm{~A}$

WHITE (11.5003) (11)LUG $(J, T), J=1.5)$

AO CONTINIIE

ENIIF ILE 11

C

C

c.

MASTER Program (contd) 


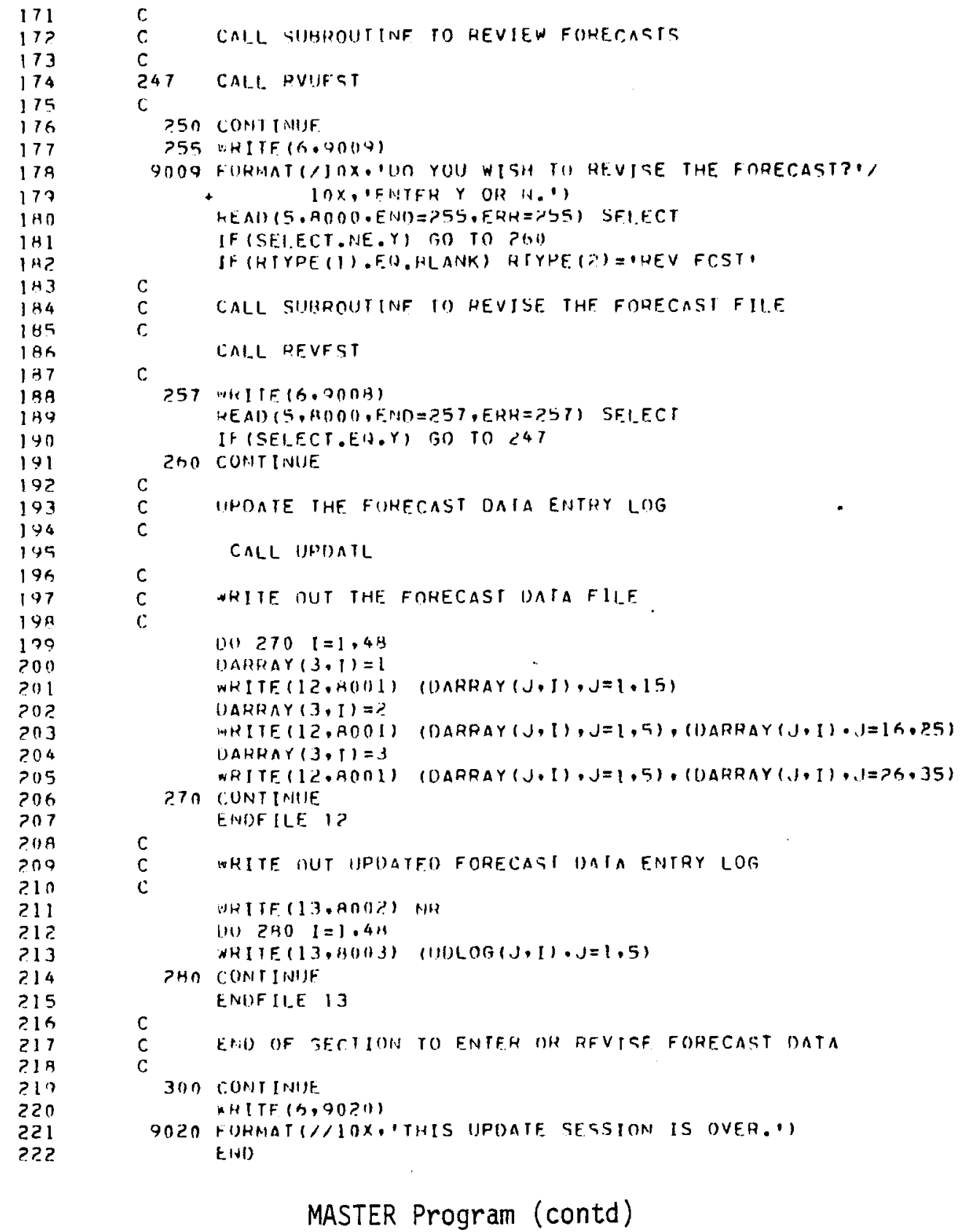




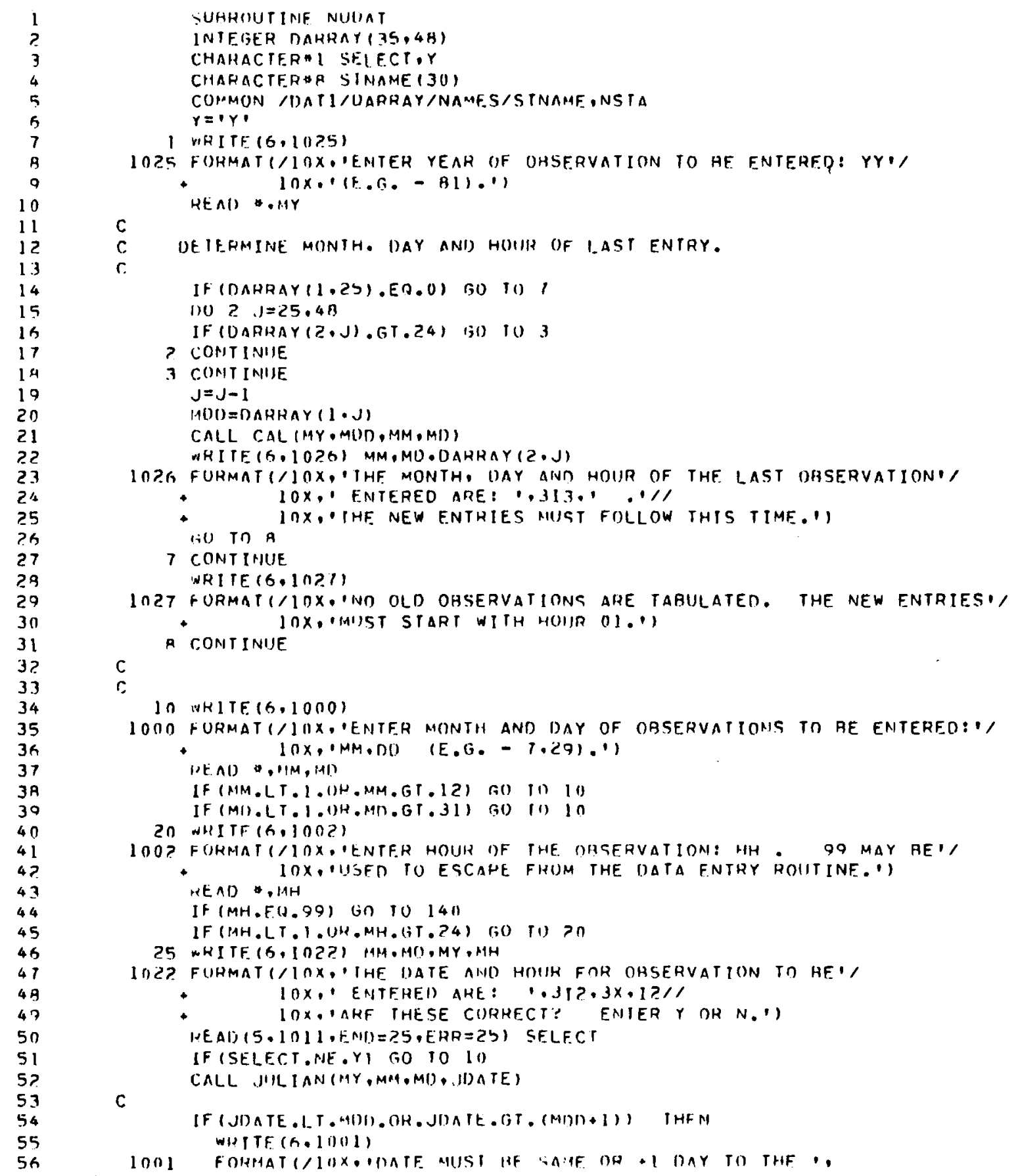

\section{Subroutine NUDAT}









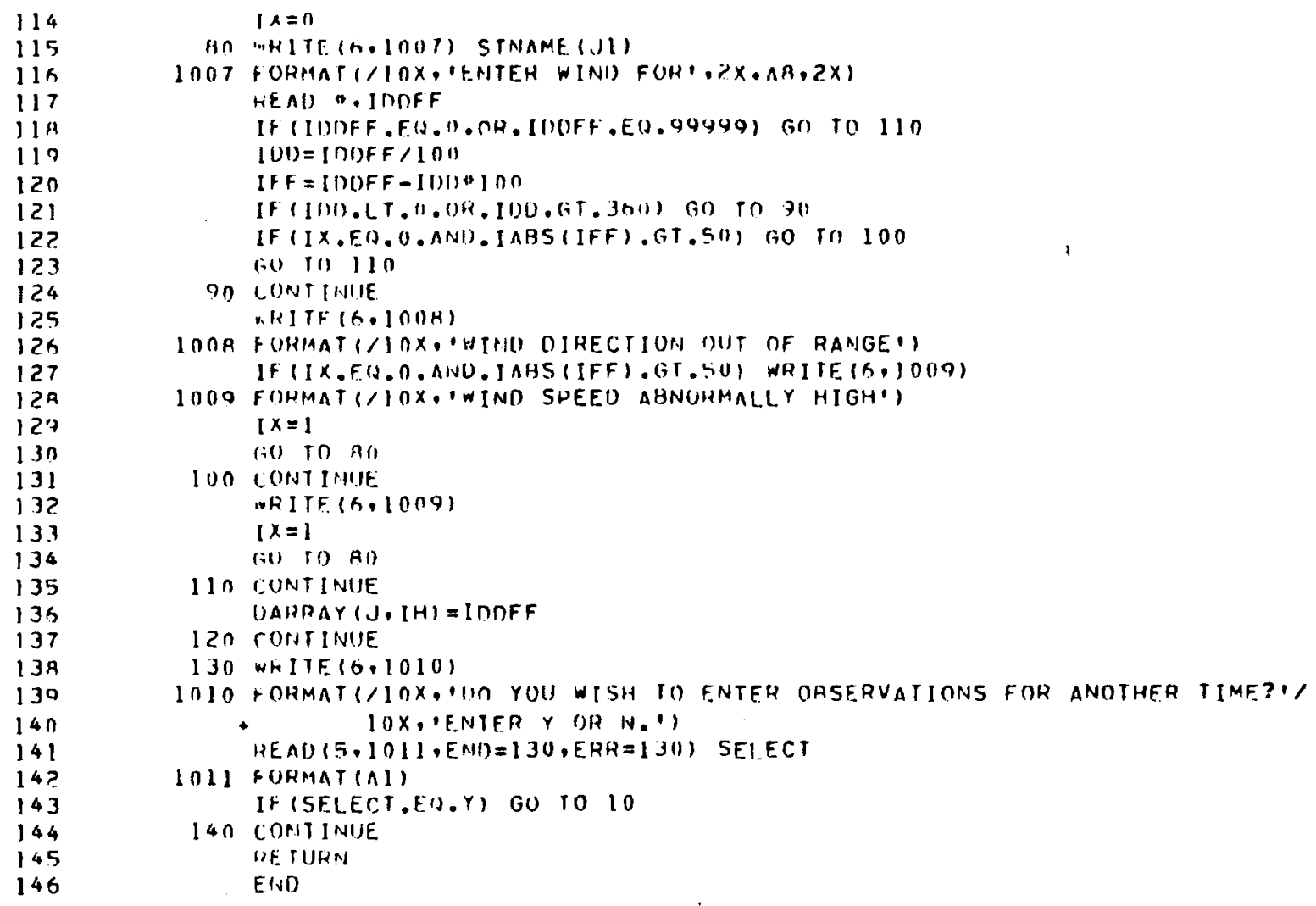

Subroutine NUDAT (contd) 


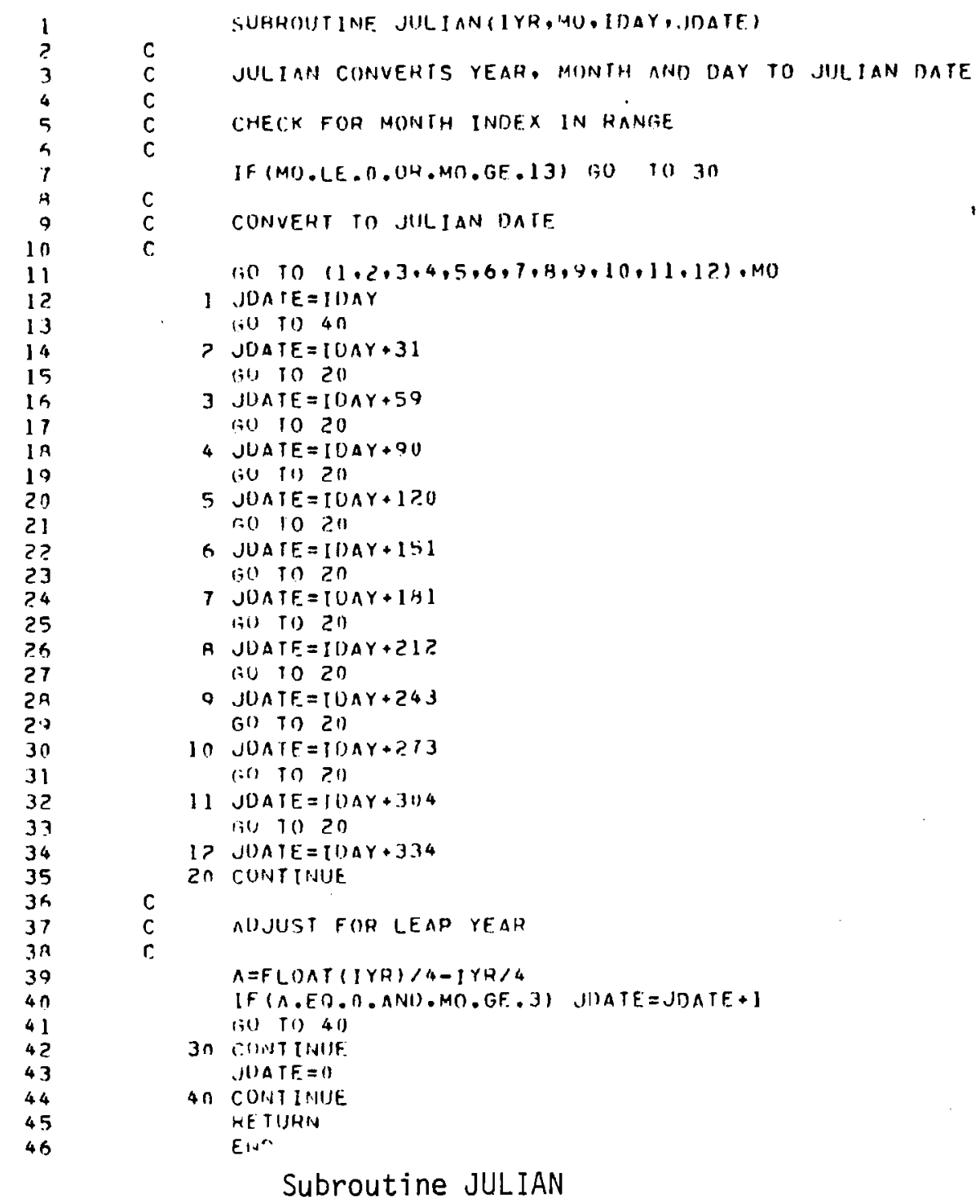




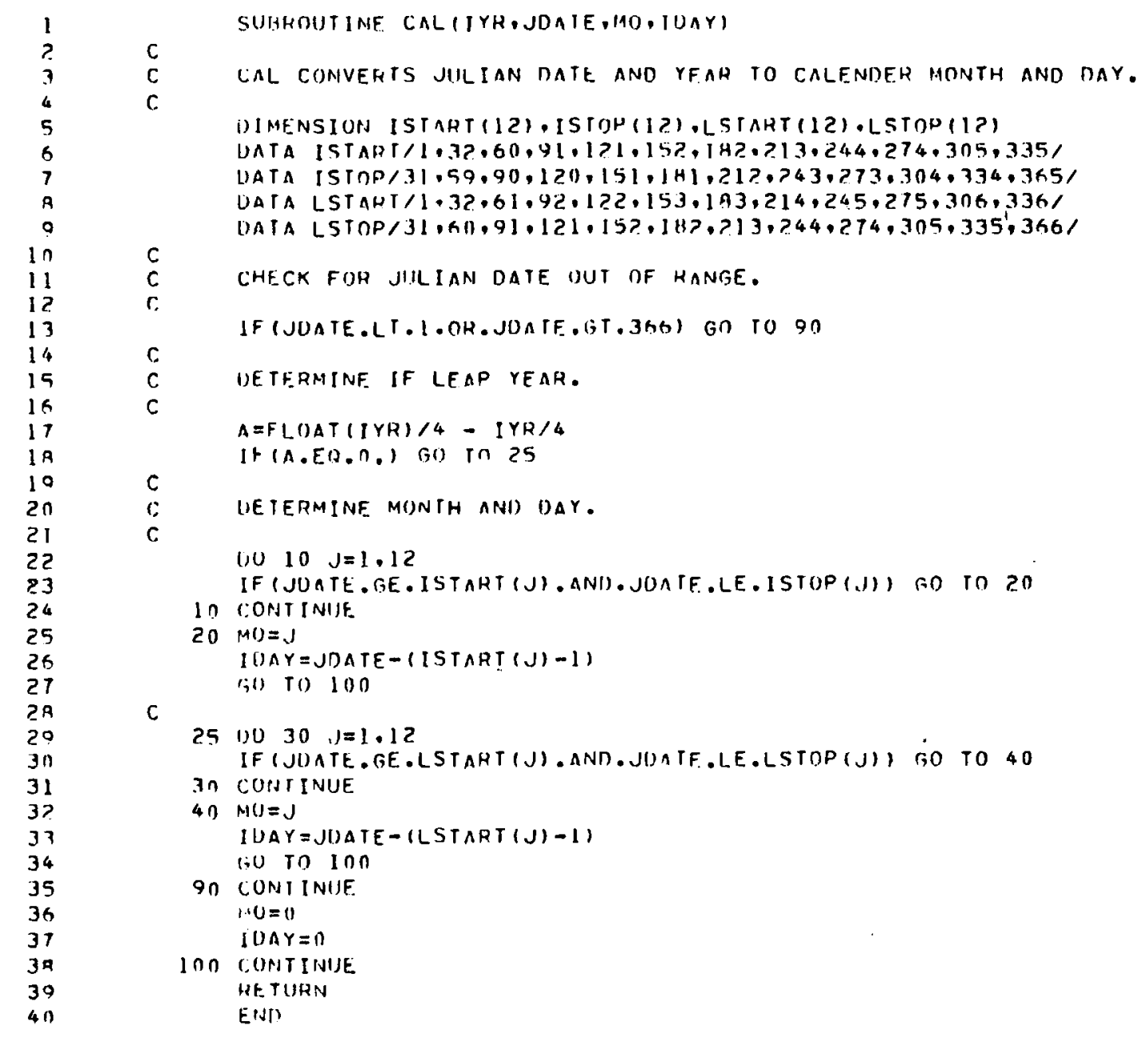

\section{Subroutine CAL}




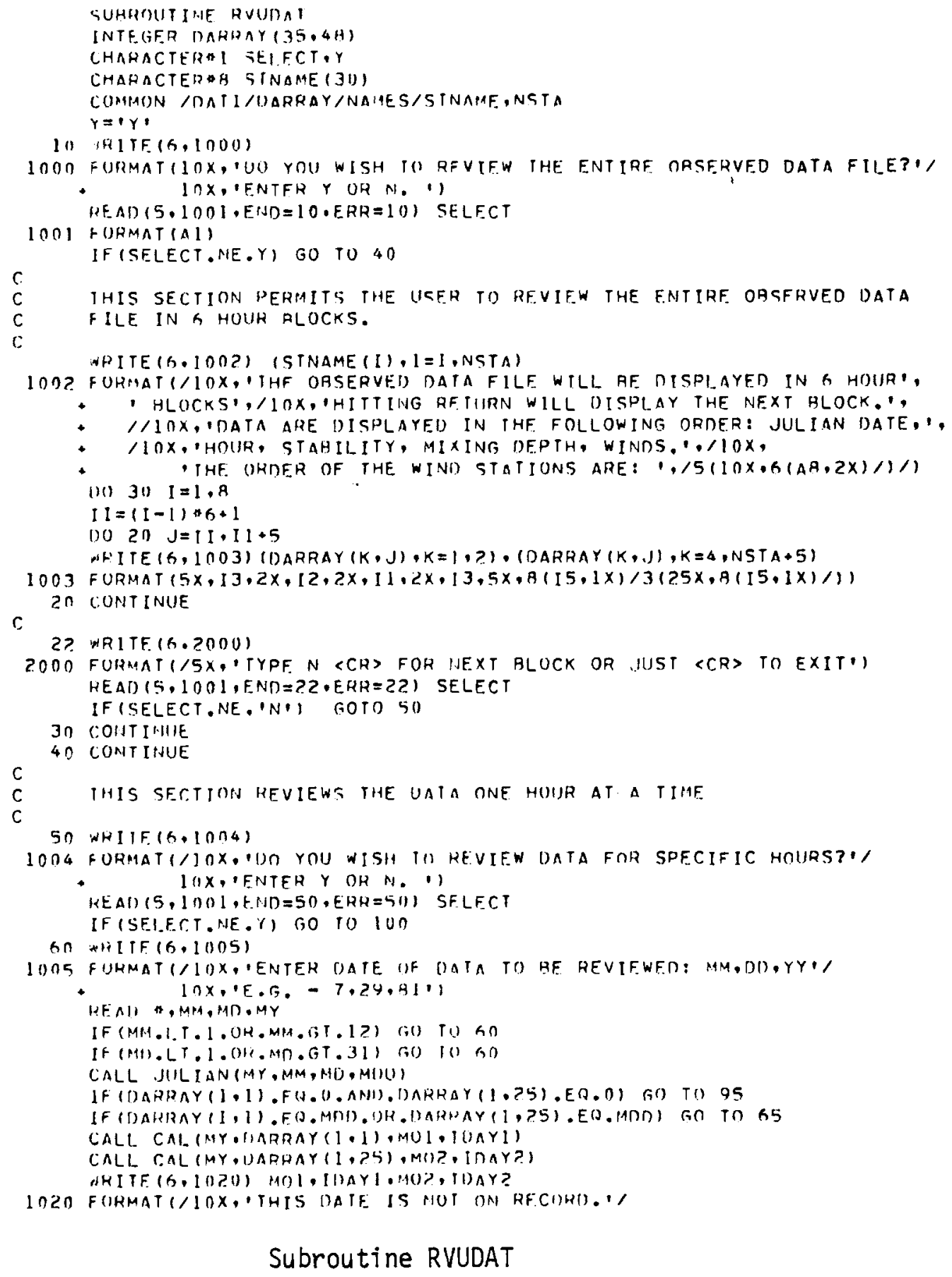

Subroutine RVUDAT 


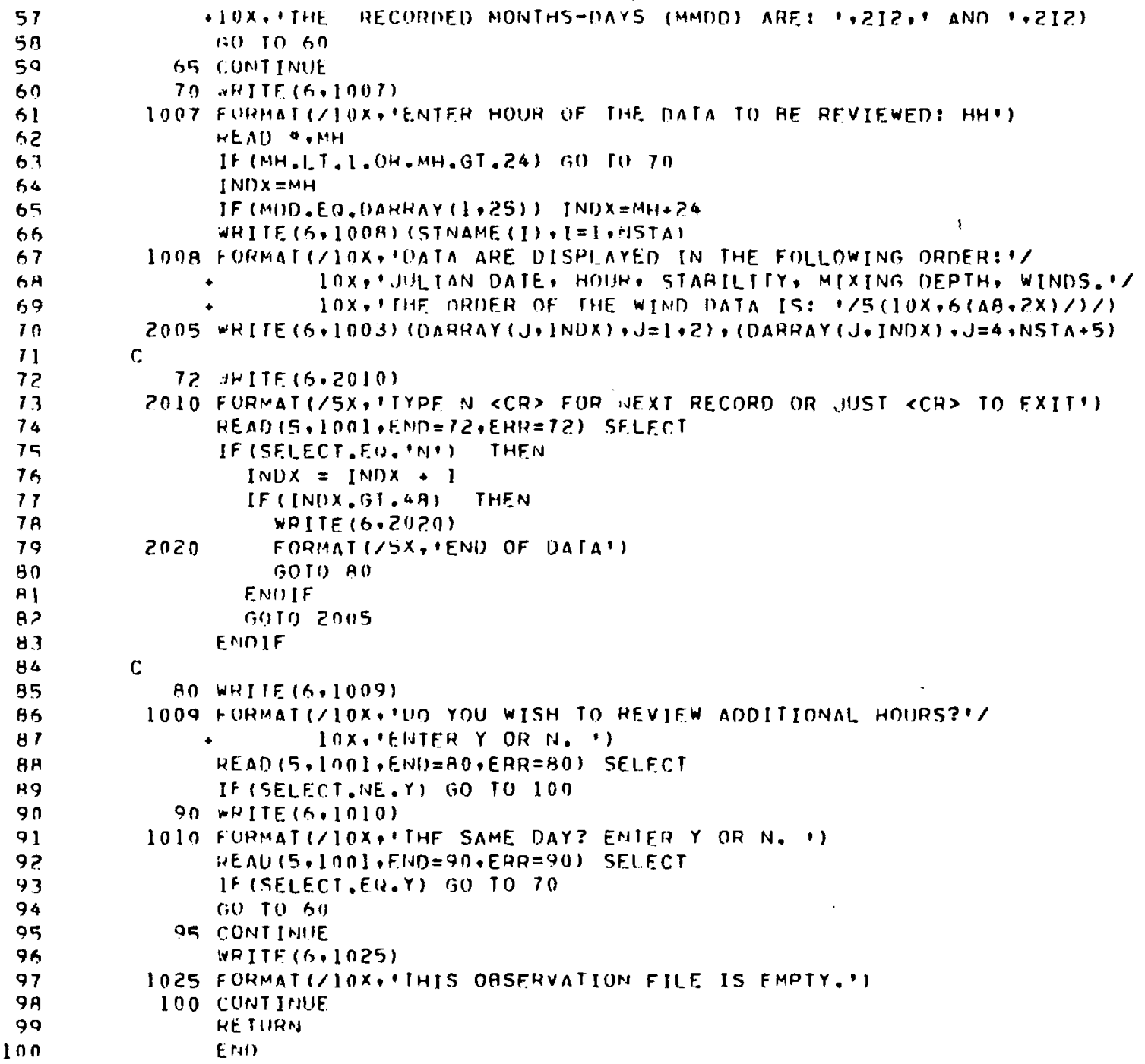

\section{Subroutine RVUDAT (contd)}




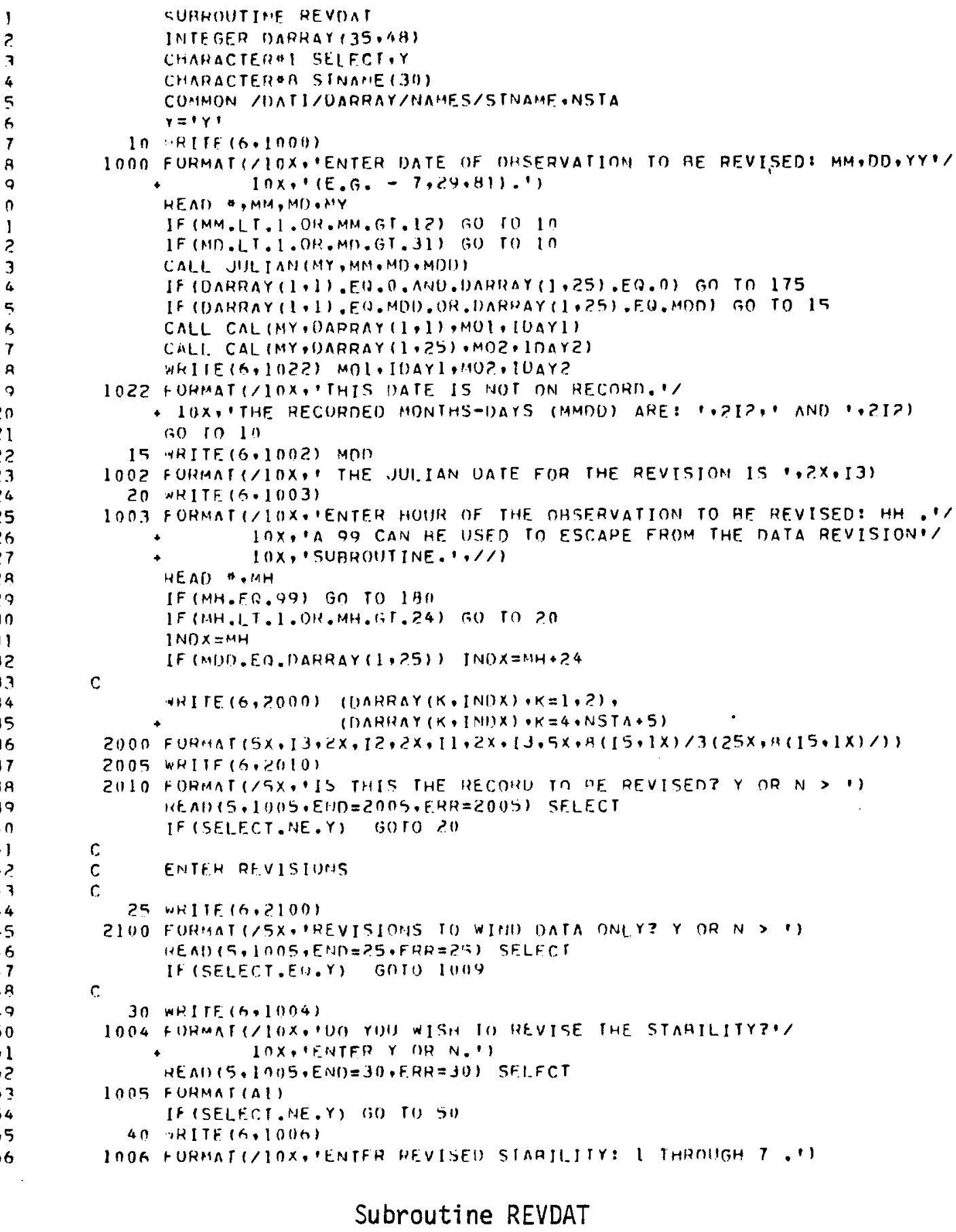

SURHOUTINF REVIIAT INTEGER DAPHAY $35, A B\}$

CHAHACTERHI SELFCT,Y

CHARACTER OA SINAME (JI))

COMMON /INTI/OARRAY/NAHES/STNAMF. NSTA $r=|Y|$

In $\because R[$ I $(6 \cdot \ln 00)$

IONO FURMATIIOX. ENTER DATE OF OHSERVATION TO RE REVISED: MM,DD,YYI

HEAN $\quad, M M, M O, \lambda$ YY

IF (MM.LT. I.OK.MM,GT.12) RO 1010

IF (MI).LT. I.OR.MN.GT.31) (\$O) TO 10

CALL JIJLIAM M MY, MN, MDOMDIU)

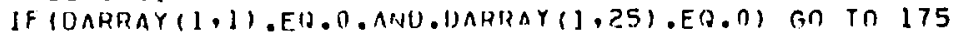

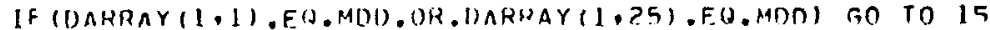

CALL CAL (NY, OAPRAY $(1,1)$, MUI, IUAYl)

CALL CAL (MY,DARRAY (1, ZS) MOZ,IMAYZ)

HKI IE (6, IOZ?) MOL, IOAYI, MOP? IUAY?

1022 + UHAAT / IOX, THIS IOATE IS NOT ON RECORN,

+ 1 (2X. "THE RECORDED MONIHS-I)AYS (MMDO) aRE: '.?I?, AND ',?I?) (8) 1010

15 .

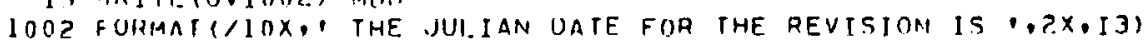

20 NसITE $(6.1003)$

IOO. FORMATI/10X. IENTER HOUR OF THE OHSERVATION TO HE HEVISED: HH .'

- IOX. 'A Qq Can he USFd to escape from the Data ReVision:

$10 \times$, , SURROUTINE. $1,1 / 1$

HEAO $\because M H$

IF (MH.FO. 99) GO TO 1 BO

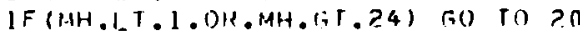

$1 N D X=A H$

C

(F (MI)D, EO, DARRAY (1.25), INOX $=N H+24$

WHITE $(6,7000)$ (UARRAY $(K, I N() X), K=1,2)$,

$+$ (I)ARHAY $(K, I N I) X) \cdot K=4, N S T A+5)$

2000 FURHAT $(5 x, 13,2 x, 12,2 x, 11,2 x \cdot 13,5 x, 4(15,1 x) / 3(25 x, 4(15,1 x) / 1)$

2005 WRIIF $(6,2010)$

2110 FOHAAT $/ / 5 X$. IS THIS THE RECORU TO DE REVISERT Y OR $N>M$ IE $\cap 1)(5.1005 . E H D=2005$. E.HR=200S) SF.LECT

IF (SELECT.NE.Y) $\$ 00 T O$ ?O

C.

C

25 WHIIF 16,2100

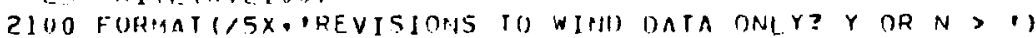
HEA!) $(5,1005, E N()=$ ?.5, FRR $=25)$ SFLFCT

IF (SELECT.EH.Y) GOTO IU119

C.

30 WHITF $(h, 1004)$

1004 FUHMATQ/10X. UUO YUU WISH IO UEVISE THE STAAILITY?'/

$+$

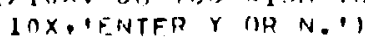

HE $A 1)(5, \mid \cap 05, E N()=30, F R H=301$ SFI.FCT

IOCS FUHMAT(A)

IF (SELFC.T.NAE, Y) (;O) TU SU

40 , $R I T F(A, 1000)$

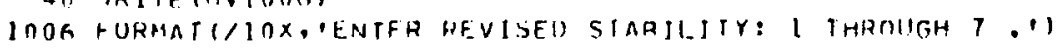

Subroutine REVDAT 


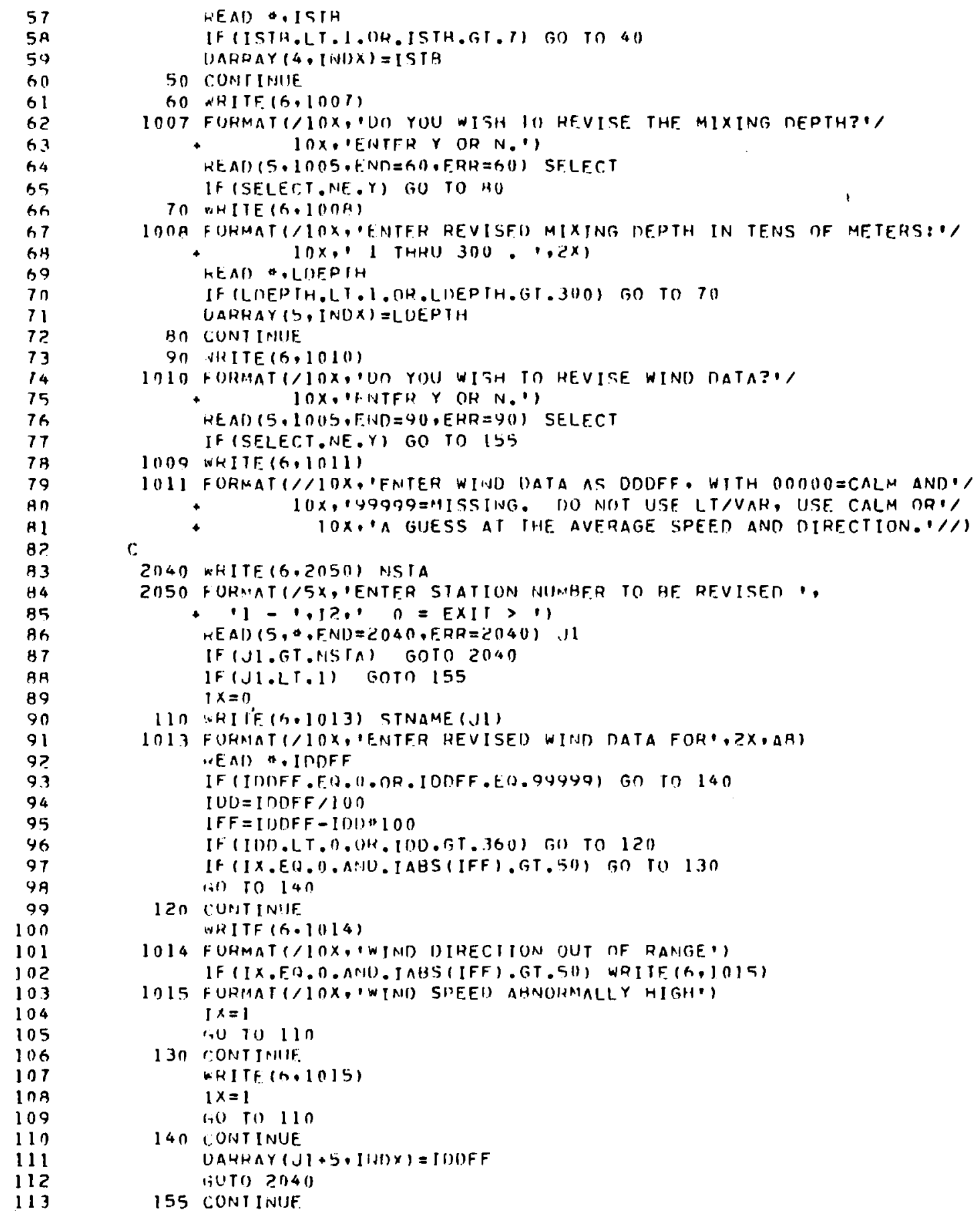

\section{Subroutine REVDAT (contd)}




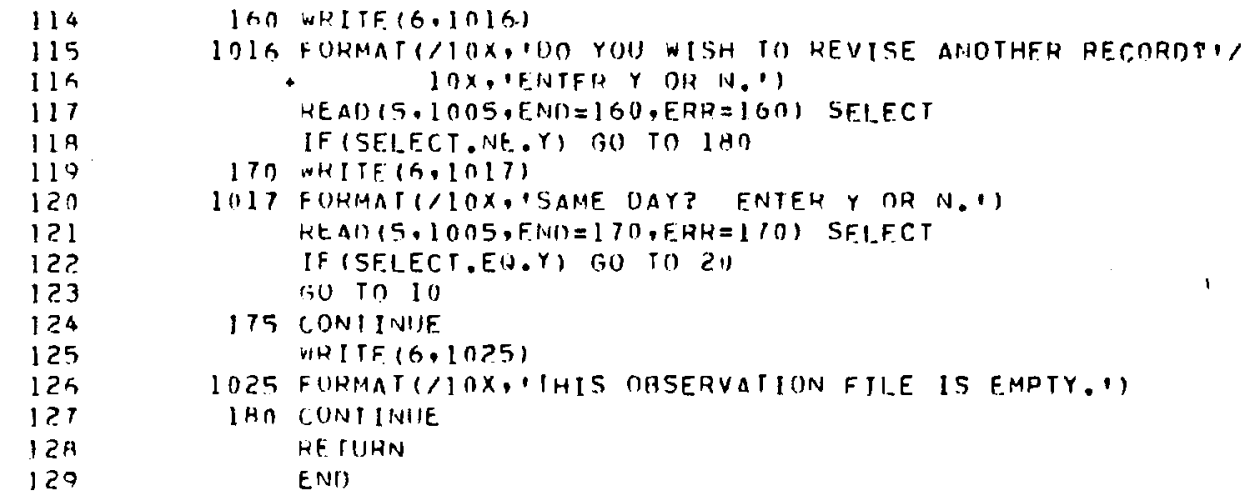

Subroutine REVDAT (contd) 


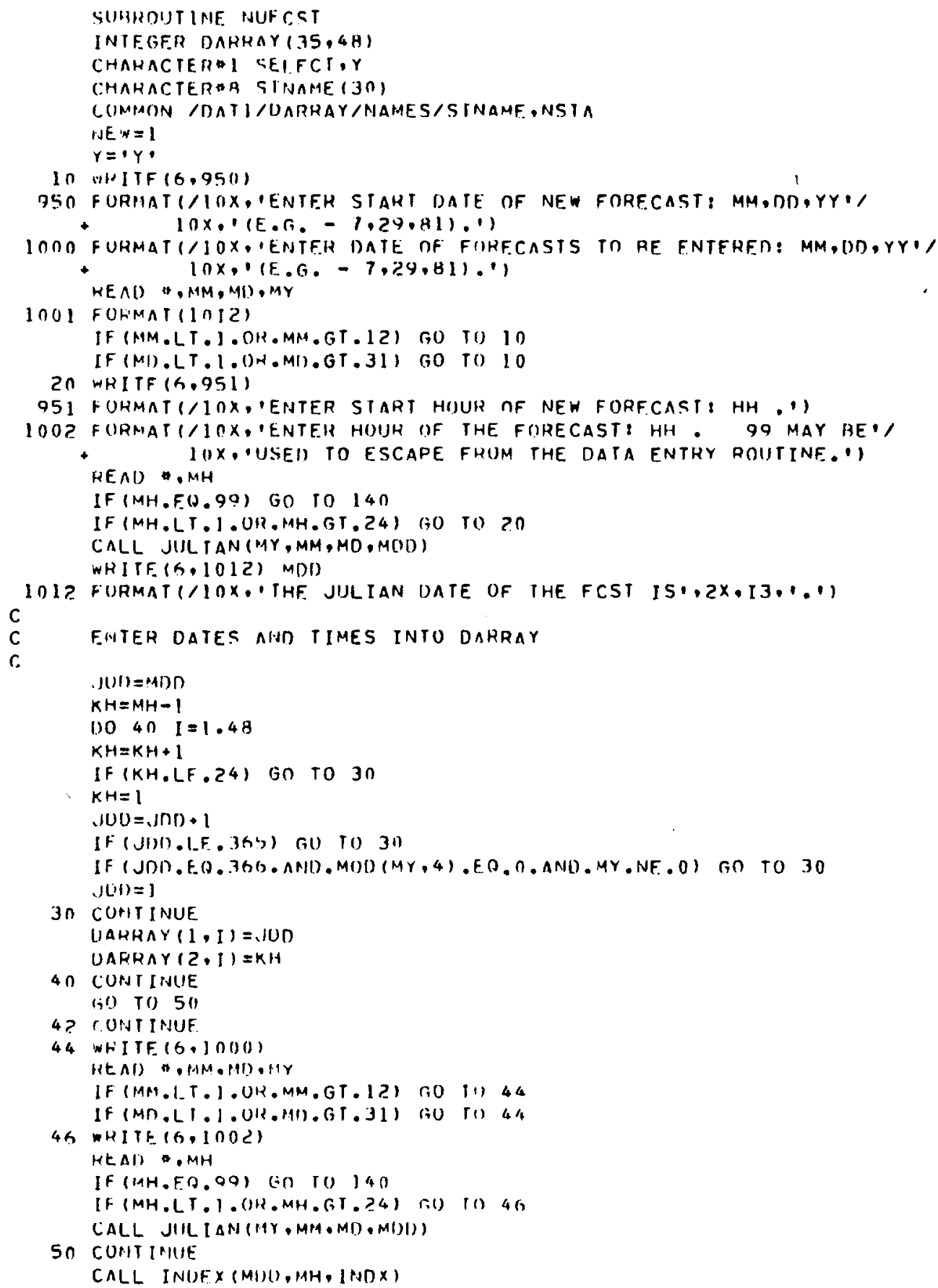

\section{Subroutine NUFCST}




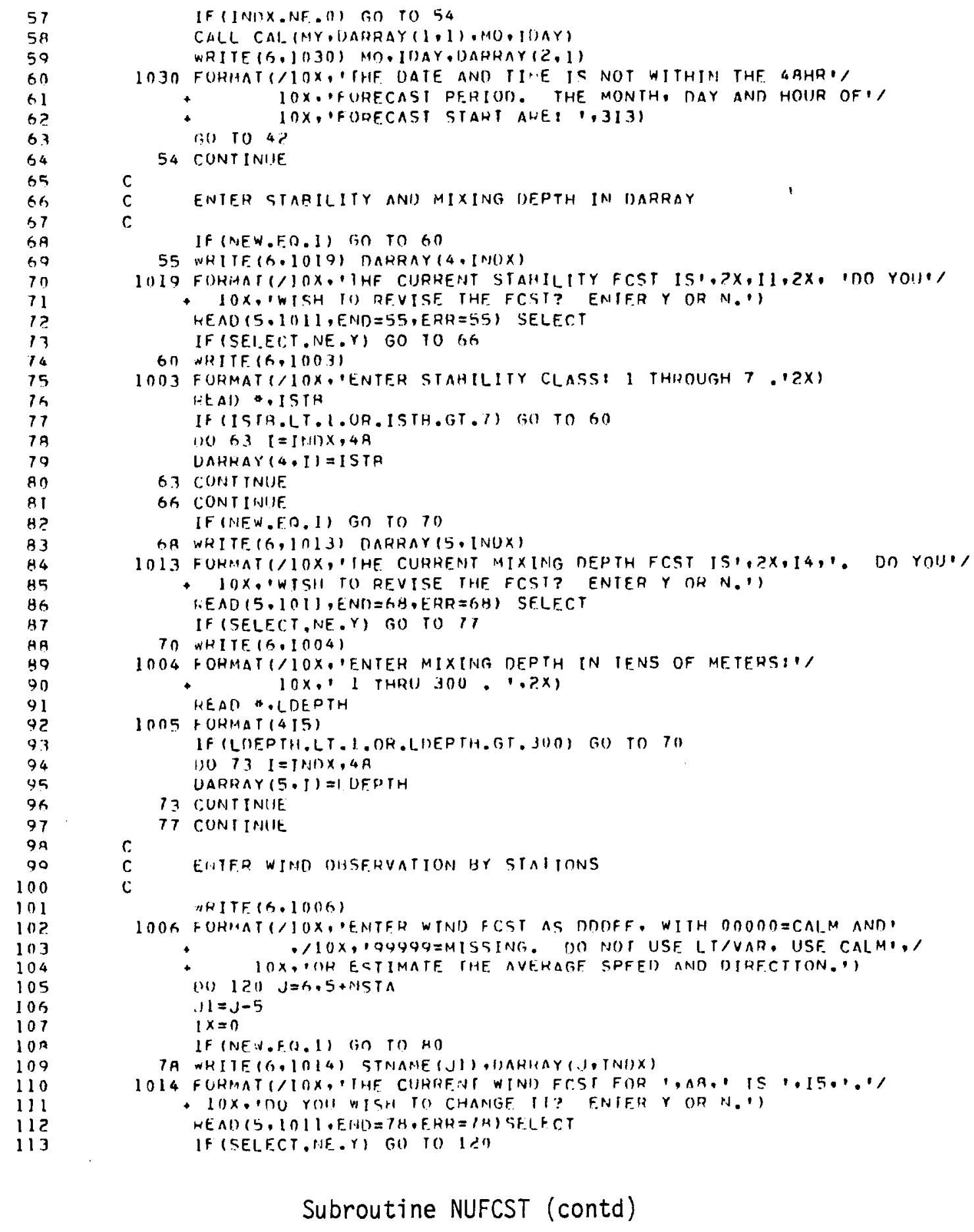




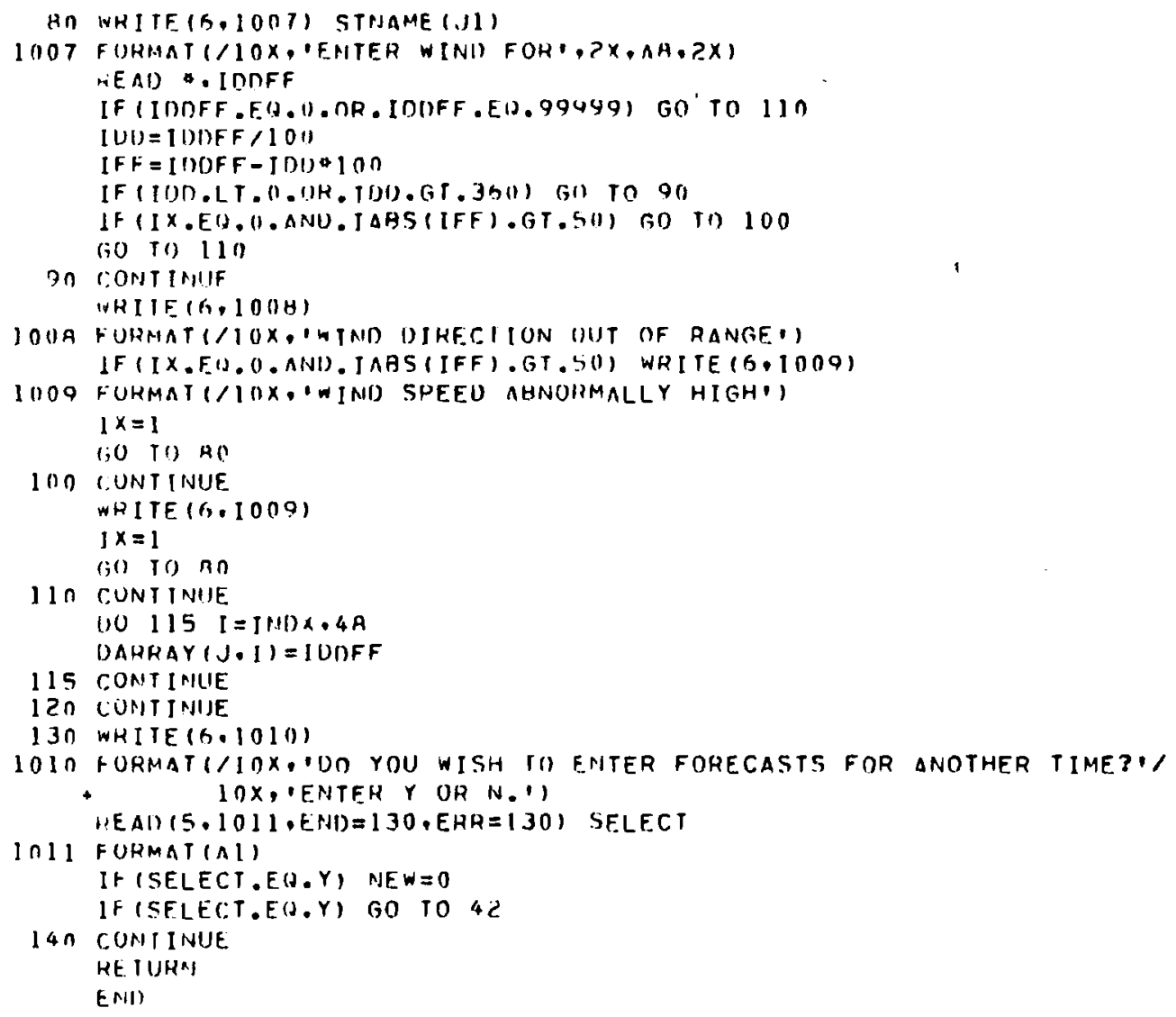

Subroutine NUFCST (contd) 


1
7
3
4
5
6
7
8
9
10
11
12
13
14
15
16
17
19
19
20
21
22
23
24
25
25
27
28

SHHROUIT INE. INUIF X(MO)O, HH, INOX)

INIEGER RAPHAY (35.4H)

COMMOIN /DATI/UARHAY

$n=0$

II) $10 \quad \mathrm{I}=1.4 \mathrm{H}$

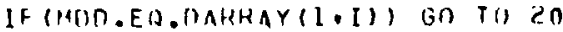

$n=k+1$

10 CONTINUE

IF $(K, F() .4 B)$ G0 1051$)$

?. C:ONT INUE

(NI) $x=K$

I $\mathrm{t}=\mathrm{K}+\mathrm{K}$

$1 E=I H+(2 A-1) \wedge H 1 ? A Y(2, I H)+1)$

$1+(I F . G T .4 B) \quad I F=4 B$

$n=1$

bo) $30 \mathrm{II}=I \mathrm{H} \cdot \mathrm{IF}$

IF (NH.EQ.DAHRAY (?.I) GO IO 40

$K=K+1$

$3 n$ CUNTINIJE.

IF KK.AT.IF) GO TO 50

$4 \pi$ CONTINUJE

INIIX $=I N U X+K$

(i) IO) 60

50 CONT INUE

IND $x=0$

gO CONTINHE

HE TURN

(EN)

\section{Subroutine INDEX}




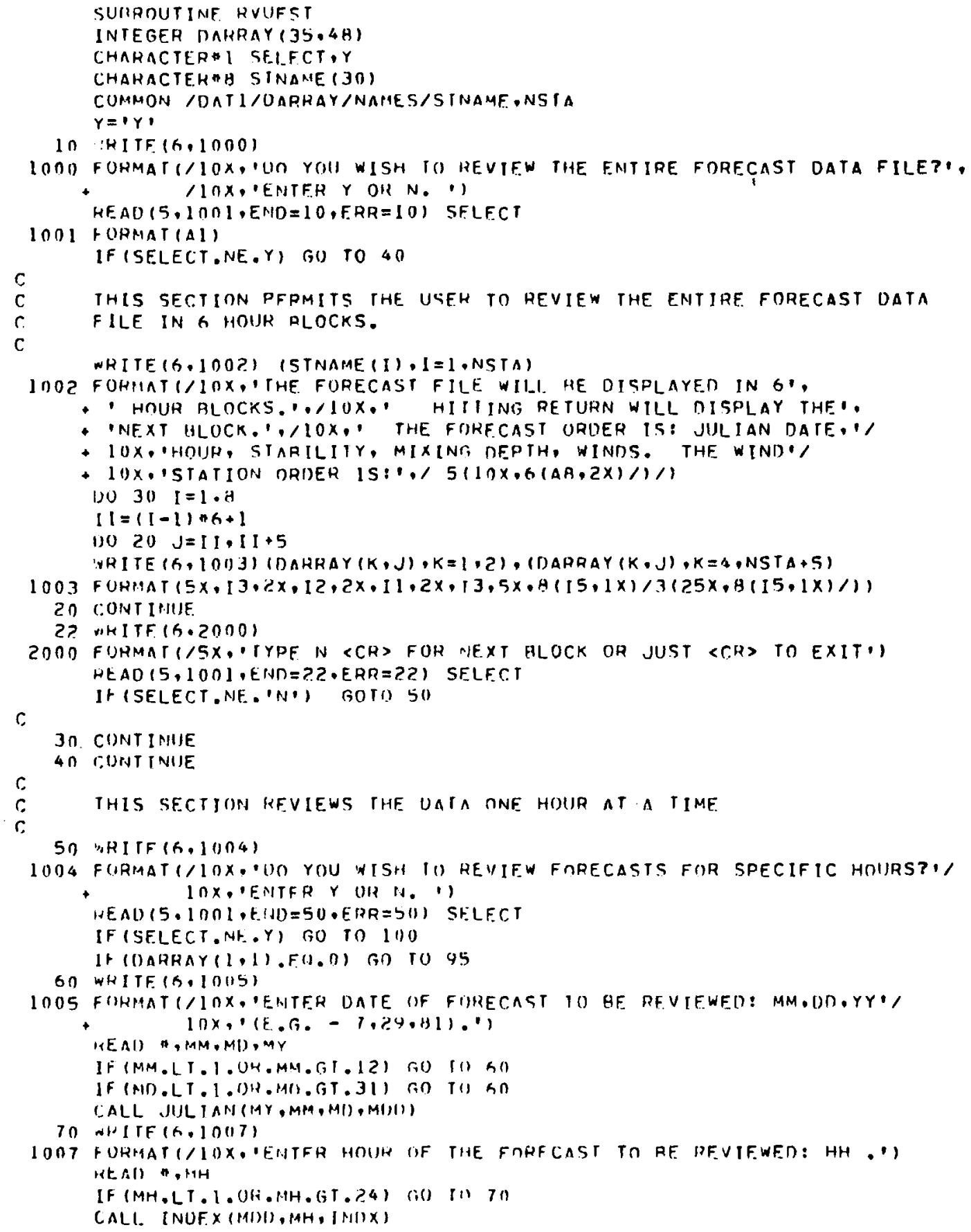

Subroutine RVUFST 


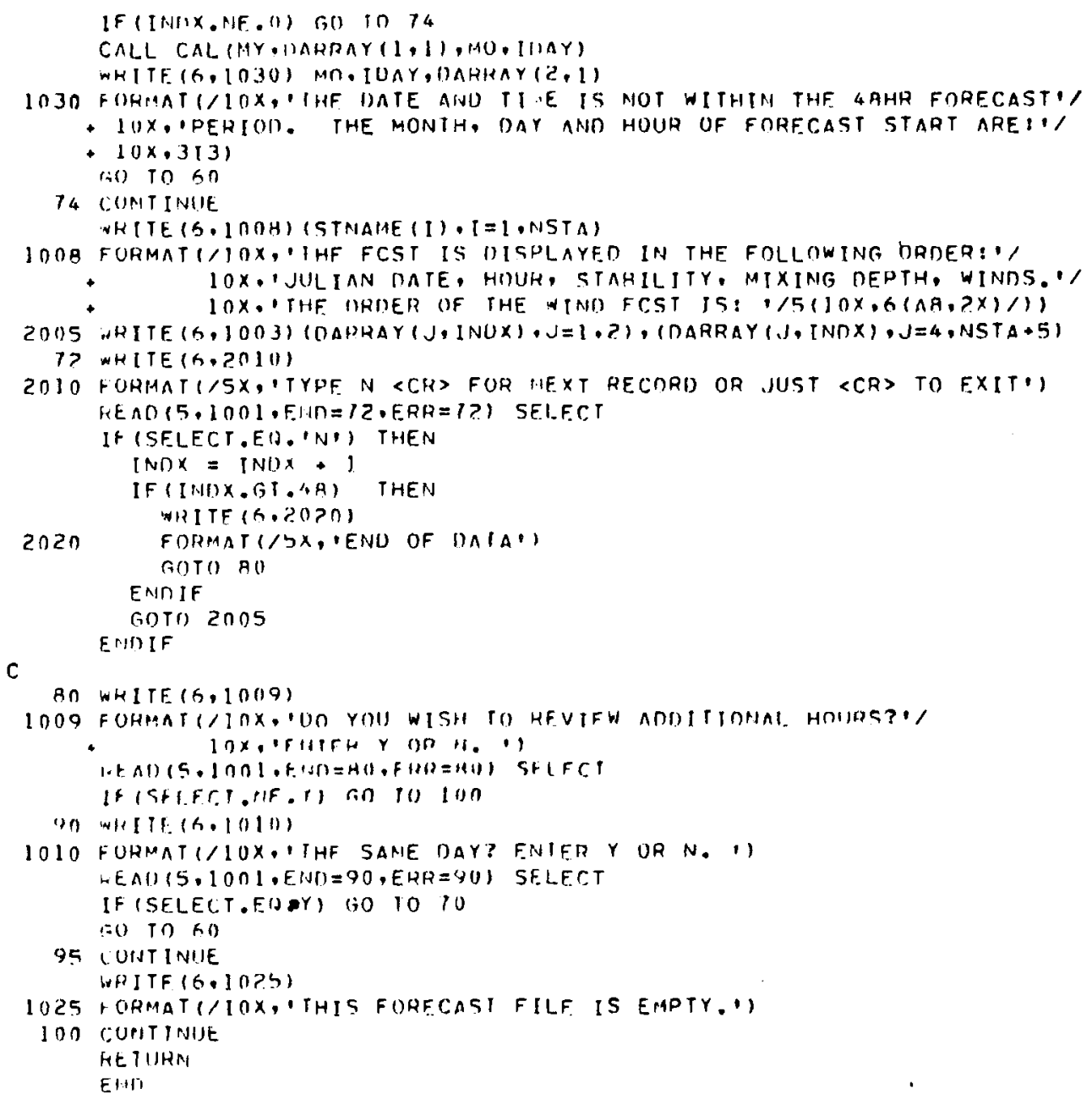

Subroutine RVUFST (contd) 


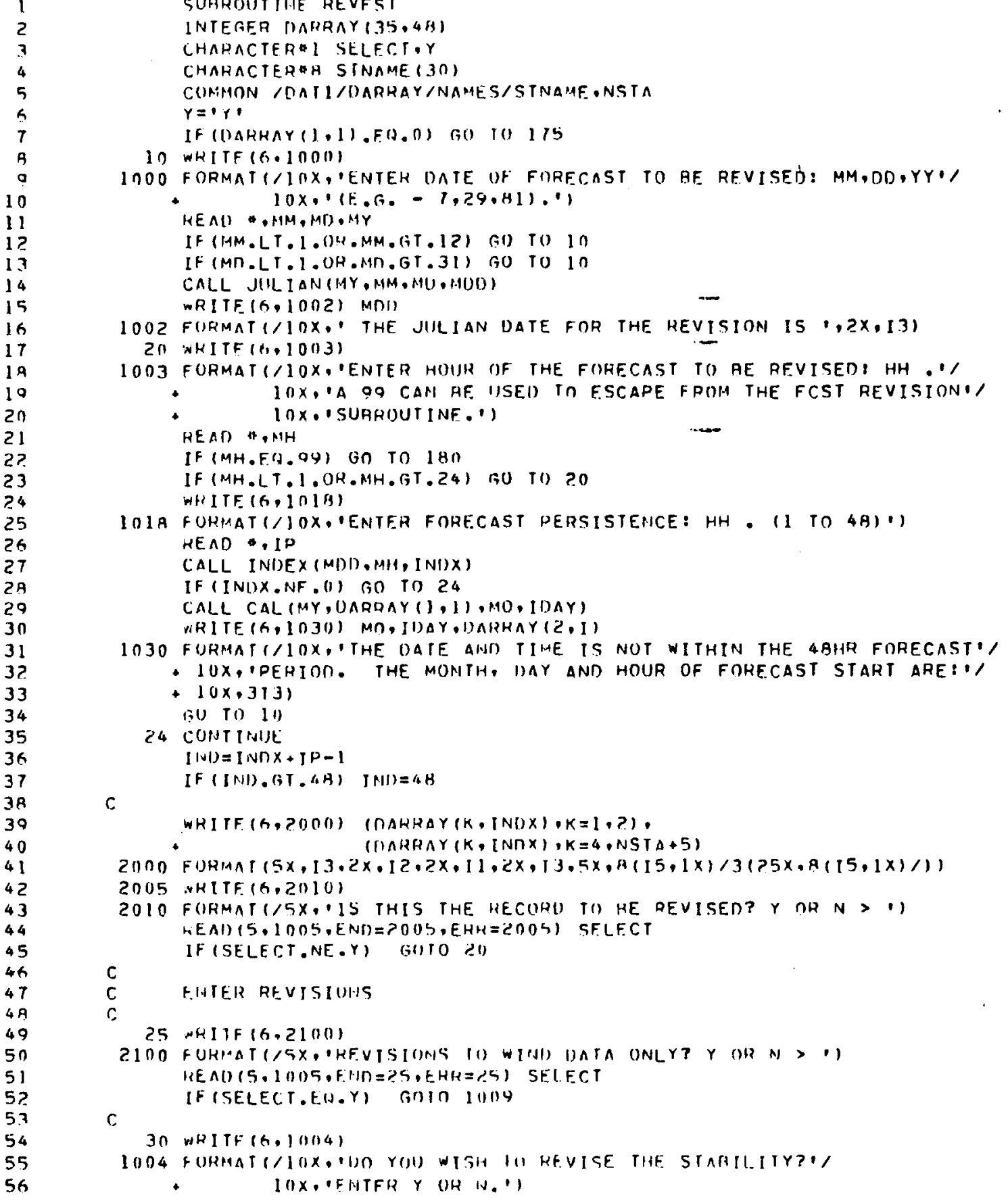

INTEGER DARRAY $(35.4 B)$

CHAHACTERAH STNAME $(30)$

CORIMON /DATI/DARRAY/NAMES/STNAME. NSTA

IF (I)ARHAY (1.1).FO. D) GO 101015

INOD FORMATU $/ 10 X$, ,ENTEK DATE UF FURFCAST TO AF RFVISED: MM,DD,YYM

KEAU $, M M, M C, M Y$

IF (HM.LT.1.O)M.MM.(BT.12) GI) TO $1 \mathrm{~A}$

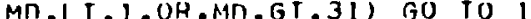

CALL JULLIAN(MY,MM, MU, HUD

3 FURMAT $/ 10 X$, 'ENTER HOUL OF THE FOHECAST TO RE REVISED? HH .'/

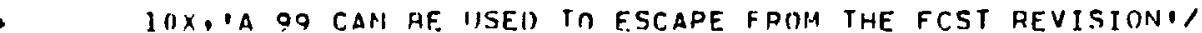

HEAD N, MH

IF (MH.F(1) OQ

IF (MH.LT.1.OR.MH.GT.24) GO TO 2O

ITF $(6,1018)$

HEAD , IP

CALL INI)EX(MD),MII, INI)X)

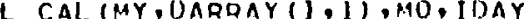

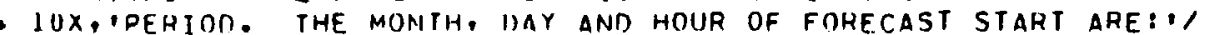

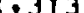

$\left.\int|N|\right)=\ln x+T P-1$

2005 *HITF $(6,20) 10)$

HEAD $(5,1005$, END)=200S, EHH=20OS) SFLFC

25 WHIIF 16,2100$\}$

2100 FUHIAT(/5X. HFVISIONS 10 WIJI) DATA ONLY? Y OH N $>M$

KEAU $(5,1005, F H M=? S$, EHH= ?.5) SE(.ECT

30 WHITF $(6,10114)$

- lOX. OFNTFR Y Uh W.'

SUHROUTIME REVFST

\section{Subroutine REVFST}




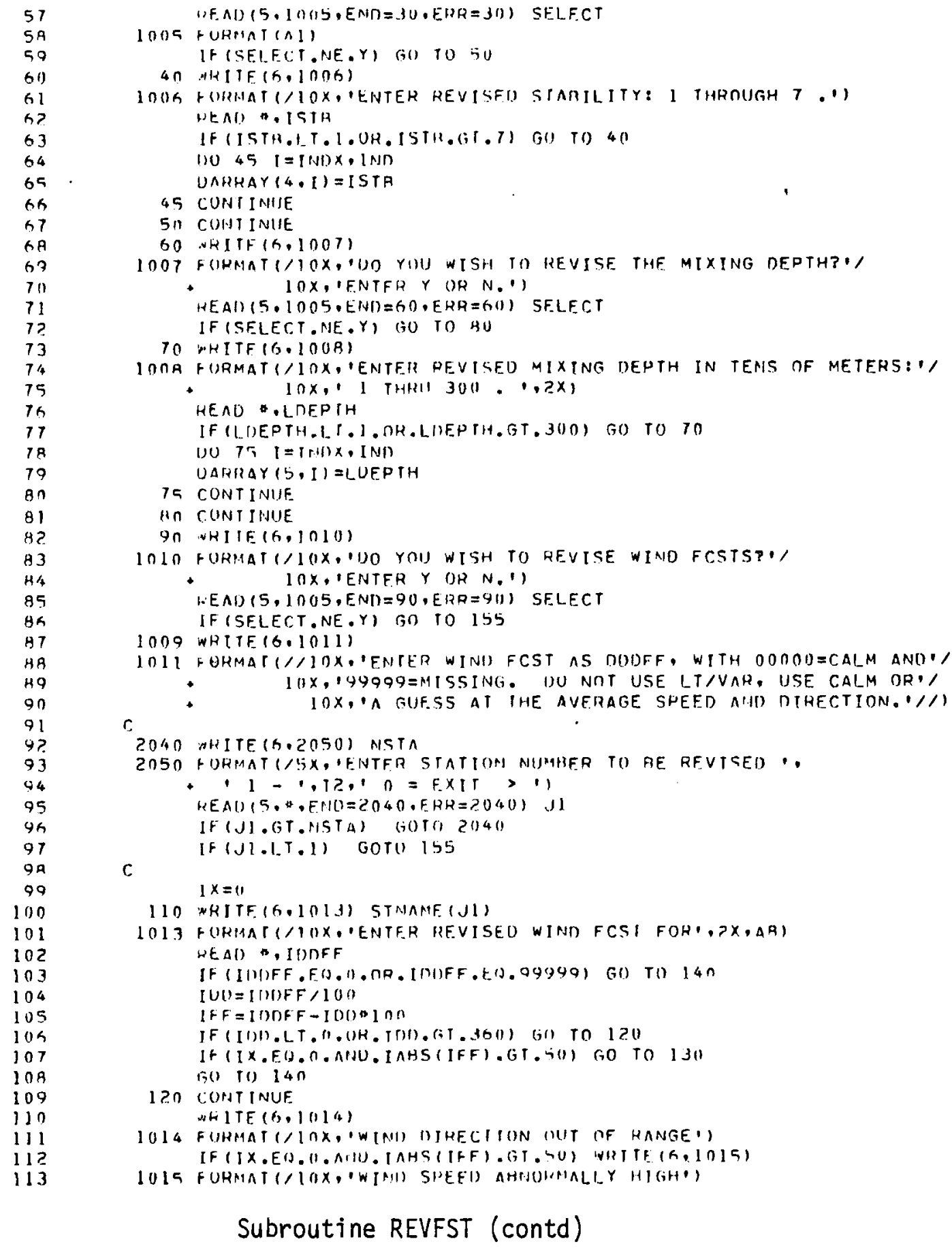




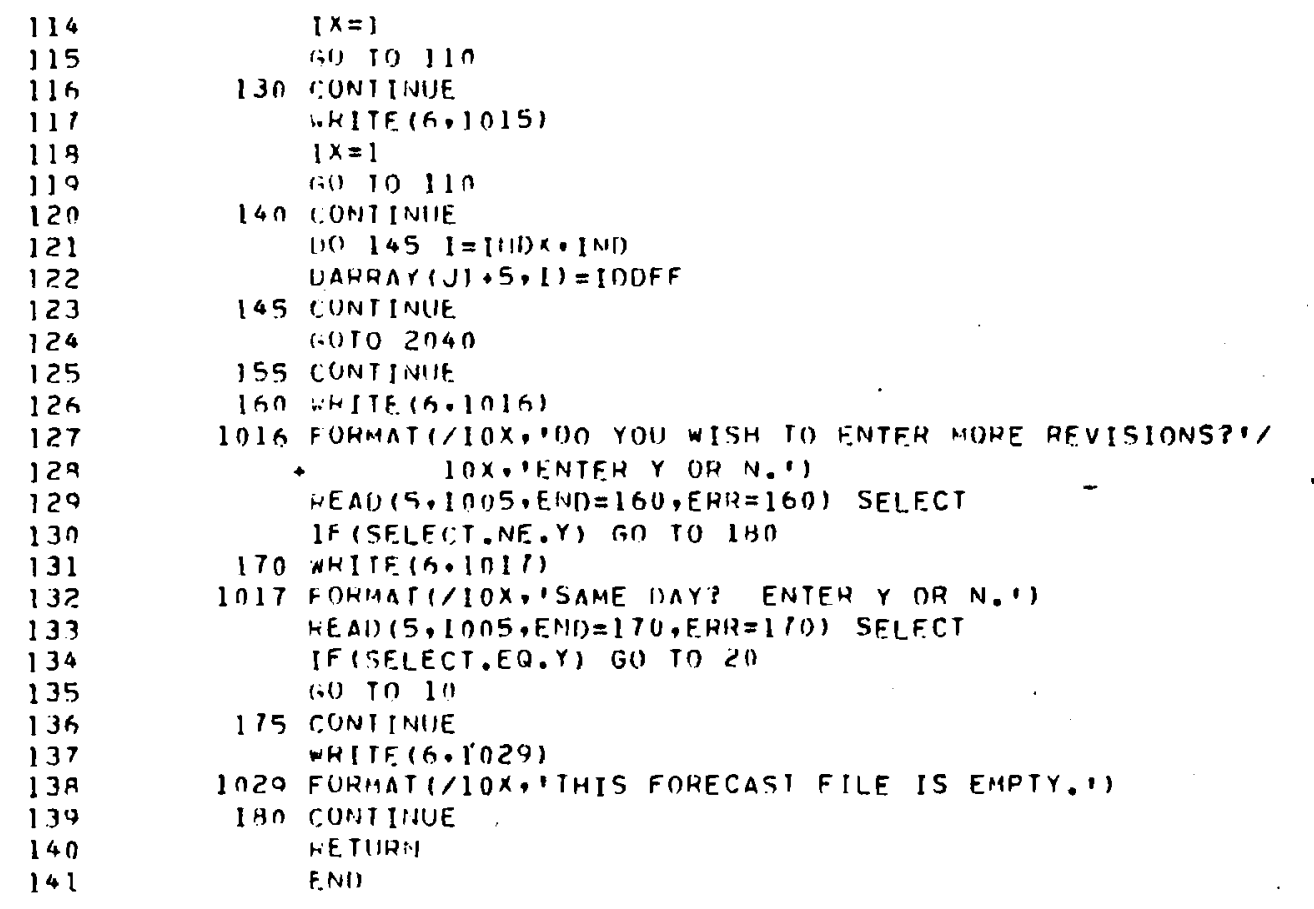

\section{Subroutine REVFST (contd)}


SUHRDUTINF UPUATL.

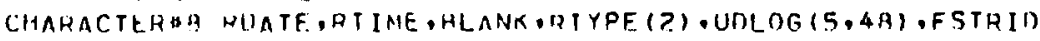
C.OMMON /I.OGS/UOL OG ORIYPE F SIHII), NR

HLANK $=$ ! ,

$c$

C

$c$

GET DATF. ANM TINE OF UPUAIF.

CALL ADATF (RUATE ORTIME)

c

c

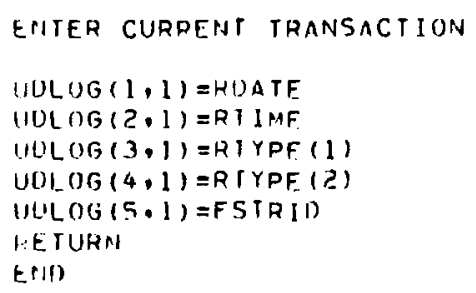

Subroutine UPDATL 


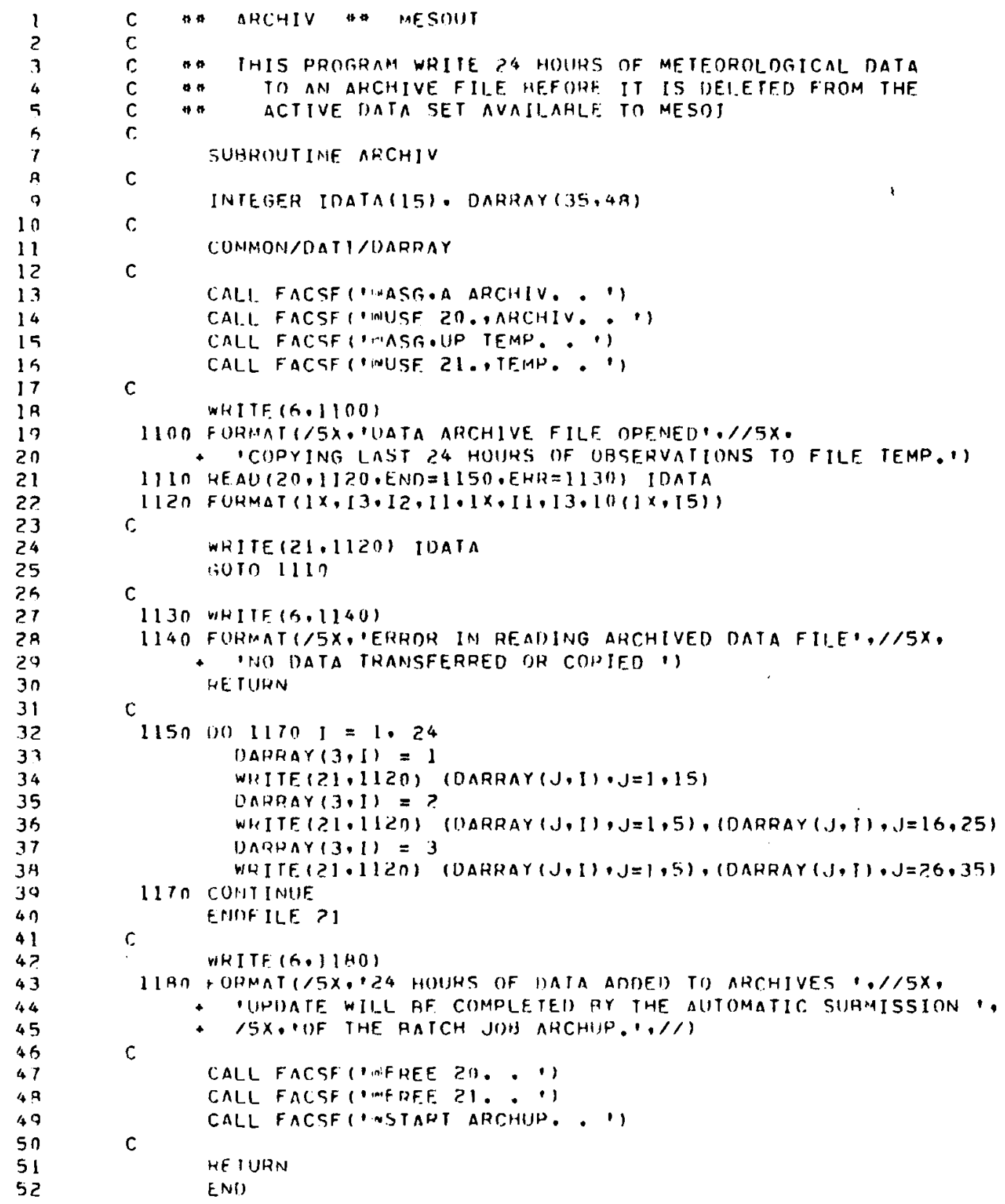

Subroutine ARCHIV 


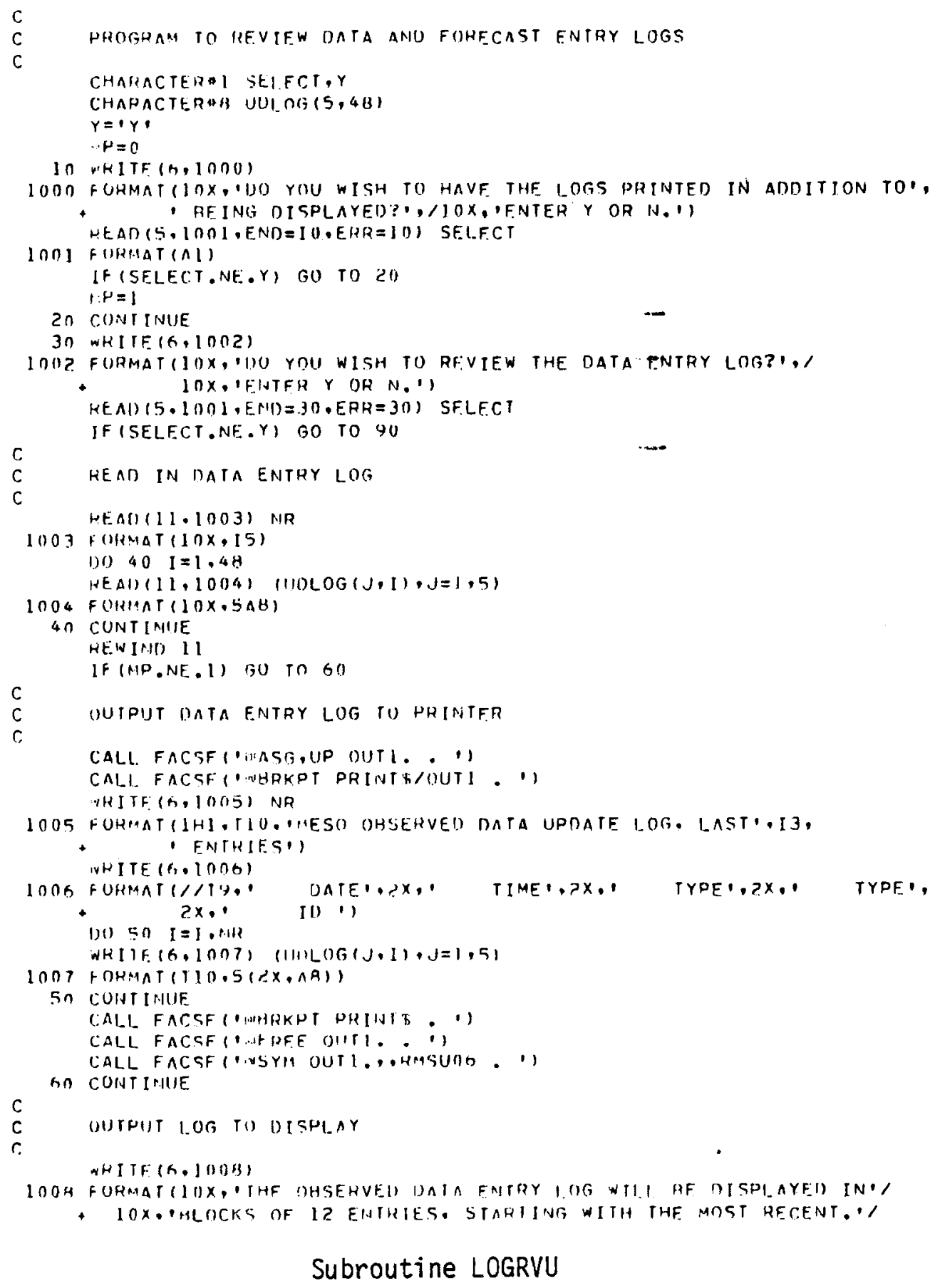

Subroutine LOGRVU 


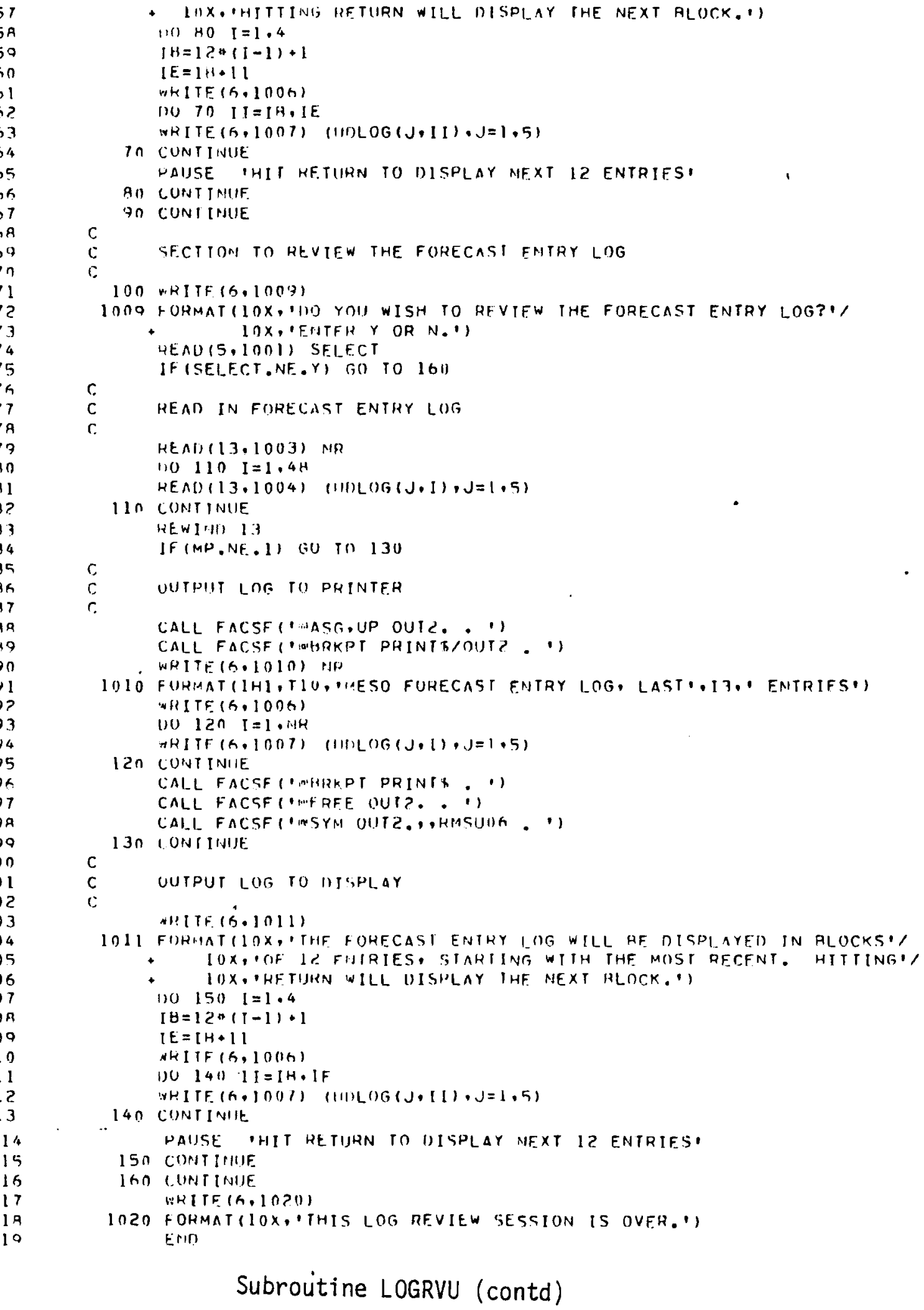

Subroutine LOGRVU (contd) 


\section{DISTRIBUTION}

No. of

Copies

OFFSITE

A. A. Churm

DOE Patent Division

9800 South Cass Avenue

Argonne, IL 60439

27 DOE Technical Information Center

ONSITE

2 DOE Richland Operations Office

H.E. Ramson

D.R. Elle

45 Pacific Northwest Laboratory

K.J. Allwine

G.F. Athey (3)

T.J. Bander

R.L. Drake

J.G. Droppo

R.K. Had lock

D.J. Hointink (15)

C.G. Lindsey

P.W. Nickola

P.M. Potter

J.V. Ramsde11 (10)

W.F. Sandusky

R.K. Woodruff

Publishing Coordination (2)

Technical Information (5) 


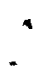

